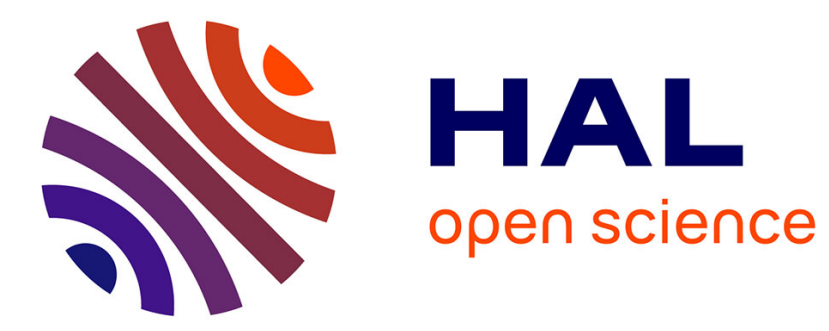

\title{
3D Benchmark on Discretization Schemes for Anisotropic Diffusion Problems on General Grids
}

Robert Eymard, Gérard Henry, Rapahele Herbin, Florence Hubert, Robert

Klofkorn, Gianmarco Manzini

\section{- To cite this version:}

Robert Eymard, Gérard Henry, Rapahele Herbin, Florence Hubert, Robert Klofkorn, et al.. 3D Benchmark on Discretization Schemes for Anisotropic Diffusion Problems on General Grids. Finite Volume for Complex Applications VI, Jun 2011, Praha, Czech Republic. pp.895-930. hal-00580549

\author{
HAL Id: hal-00580549 \\ https://hal.science/hal-00580549
}

Submitted on 28 Mar 2011

HAL is a multi-disciplinary open access archive for the deposit and dissemination of scientific research documents, whether they are published or not. The documents may come from teaching and research institutions in France or abroad, or from public or private research centers.
L'archive ouverte pluridisciplinaire $\mathbf{H A L}$, est destinée au dépôt et à la diffusion de documents scientifiques de niveau recherche, publiés ou non, émanant des établissements d'enseignement et de recherche français ou étrangers, des laboratoires publics ou privés. 


\title{
3D Benchmark on Discretization Schemes for Anisotropic Diffusion Problems on General Grids
}

\author{
Robert Eymard, Gérard Henry, Raphaèle Herbin, Florence Hubert, \\ Robert Klöfkorn and Gianmarco Manzini
}

\begin{abstract}
We present a number of test cases and meshes that were designed as a benchmark for numerical schemes dedicated to the approximation of threedimensional anisotropic and heterogeneous diffusion problems. These numerical schemes may be applied to general, possibly non conforming, meshes composed of tetrahedra, hexahedra and quite distorted general polyhedra. A number of methods were tested among which conforming finite element methods, discontinuous Galerkin finite element methods, cell-centered finite volume methods, discrete duality finite volume methods, mimetic finite difference methods, mixed finite element methods, and gradient schemes. We summarize the results presented by the participants to the benchmark, which range from the number of unknowns, the approximation errors of the solution and its gradient, to the minimum and maximum values and energy. We also compare the performance of several iterative or direct linear solvers for the resolution of the linear systems issued from the presented schemes.
\end{abstract}

Key words: Anisotropic and heterogeneous medium, diffusion problem, numerical schemes for general polyhedral meshes, non-conforming meshes, 3D benchmark.

MSC2010: 65N08, 65N30, 65Y20, 76S05

Robert Eymard

Université Paris-Est, France, e-mail: Robert.Eymard@univ-mlv. fr

Gérard Henry

Université Aix-Marseille, France, e-mail: Gerard.Henry@latp.univ-mrs. fr

Raphaèle Herbin

Université Aix-Marseille, France, e-mail: Raphaele. Herbinelatp. univ-mrs. fr

Florence Hubert

Université Aix-Marseille, France, e-mail: Florence.Hubertelatp.univ-mrs.fr

Robert Klöfkorn

Universität Freiburg, Germany, e-mail: robertk@mathematik .uni-freiburg. de

Gianmarco Manzini

IMATI-CNR and CeSNA-IUSS Pavia, Italy, e-mail: Marco.Manzini@imati.cnr.it 


\section{Introduction}

The two-dimensional (2D) anisotropy benchmark organized in 2007-2008 [21] provided a better understanding of the relative properties of a huge number of numerical schemes in terms of robustness, accuracy, problem size (number of degrees of freedom and matrix size), quality of the numerical approximation (maximum/minimum principles), etc. Nonetheless, a direct extrapolation of these results to three-dimensional (3D) problems is not possible because of the much higher complexity of the meshes involved in a 3D calculation and the larger size of the resulting linear systems. Hence, a new benchmark was organized between the end of 2010 and the beginning of 2011 with the additional goal of comparing CPU times versus accuracy.

A number of anisotropic and heterogeneous diffusion problems, associated with general, possibly non-conforming, 3D grids, were proposed in order for the participants to test a variety of numerical schemes. The participants were expected to provide information about the results obtained in these test cases and to use a set of solvers made available by the benchmark organizers for the linear systems arising from the discretization. In order to ensure a fair comparison of CPU times, all linear systems were solved by the same program implemented sequentially on the same computer, located at Université Aix-Marseille, France.

In most test cases the domain $\Omega$ is the unit cube; the boundary of $\Omega$ is denoted by $\Gamma$. We consider the steady diffusion problem with either homogeneous or nonhomogeneous Dirichlet conditions on the boundary that is formulated in strong form as:

$$
\begin{aligned}
-\nabla \cdot(\mathbf{K} \nabla u)=f & \text { on } \Omega, \\
u=\bar{u} & \text { on } \Gamma,
\end{aligned}
$$

where $\mathbf{K}: \Omega \rightarrow \mathbb{R}^{3 \times 3}$ is the diffusion tensor, $f$ is the source term and $\bar{u}$ is the Dirichlet boundary condition. The tensor fields $\mathbf{K}$ that we consider in the benchmark test cases are, as usual, strongly elliptic in $\Omega$, i.e., each $\mathbf{K}$ is given by a field of symmetric matrices whose eigenvalues are uniformly bounded from above and from below by two strictly positive values. The data $f$ and $\bar{u}$ of the problem are determined in accordance with the given exact solution and the diffusion field of each test case.

The paper is organized as follows. In Section 2, we present the five test cases, each one being specified by the shape of the computational domain, the exact solution, the diffusion field, and the set of meshes to be used. In Section 3, we briefly describe the linear solvers that were proposed for the resolution of the linear systems issued from the different numerical schemes. In Section 4, we list the participants to the benchmark and the numerical method that they used. In Section 5, we present the nature of the results obtained from the participants.

Final conclusions are drawn in Section 6. The tables and figures of results are given in Section 7. 


\section{The test cases and the meshes}

The test cases are summarized in Table 1, where we specify, for each test case, the shape of the computational domain $\Omega$, the label of the permeability tensor, the label of the exact solution and the name of the mesh family. For more details about the meshes and other data, see at the URL:

http://www.latp.univ-mrs.fr/latp_numerique/?q=node/4,

where mesh data files can be downloaded.

\begin{tabular}{|c|c|c|c|c|}
\hline Test Case & Domain & $\begin{array}{c}\text { Permeability } \\
\mathbf{K}(x, y, z)\end{array}$ & $\begin{array}{c}\text { Solution } \\
u(x, y, z)\end{array}$ & Meshes \\
\hline $\begin{array}{c}\text { Test 1 } \\
\text { Mild anisotropy }\end{array}$ & Unit cube & $\mathbf{K}_{1}(x, y, z)$ & $u_{1}(x, y, z)$ & $\begin{array}{c}\text { Tetrahedral (B) } \\
\text { Voronoi (C) } \\
\text { Kershaw (D) } \\
\text { Checkerboard (I) }\end{array}$ \\
\hline $\begin{array}{c}\text { Test 2 } \\
\text { Heterogeneity } \\
\text { and anisotropy }\end{array}$ & Unit cube & $\mathbf{K}_{2}(x, y, z)$ & $u_{2}(x, y, z)$ & Prism (F) \\
\hline $\begin{array}{c}\text { Test 3 } \\
\text { Random meshes }\end{array}$ & $\begin{array}{c}\text { Determined } \\
\text { by the mesh }\end{array}$ & $\mathbf{K}_{3}(x, y, z)$ & $u_{3}(x, y, z)$ & Random (AA) \\
\hline $\begin{array}{c}\text { Test 4 } \\
\text { The well }\end{array}$ & $\Omega_{4}$ & $\mathbf{K}_{4}(x, y, z)$ & $u_{4}(x, y, z)$ & Well (BB) \\
\hline $\begin{array}{c}\text { Test 5 } \\
\text { Locally refined }\end{array}$ & Unit cube & $\mathbf{K}_{5}(x, y, z)$ & $u_{5}(x, y, z)$ & Locally refined (H) \\
\hline
\end{tabular}

Table 1 The test cases

The meshes are presented in Figure 1.
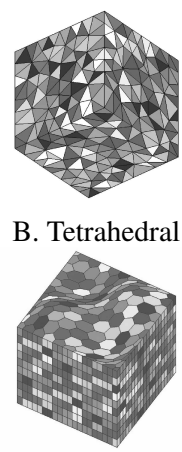

F. Prism

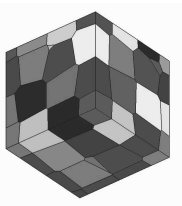

C. Voronoi

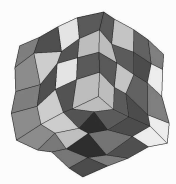

AA. Random

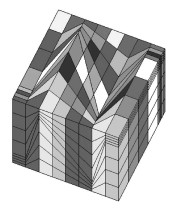

D. Kershaw

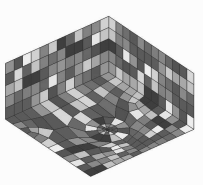

BB. Well

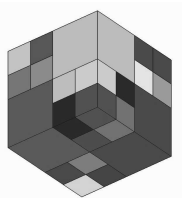

I. Checkerboard

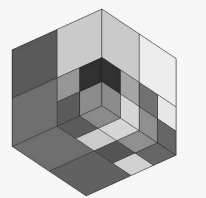

H. Locally refined

Fig. 1 The different meshes.

The data labeled in Table 1 (permeability tensor and exact solution for all test cases and computational domain for Test Cases 4 and 5) are as follows. 
1. Test Case 1. We consider a constant, anisotropic permeability tensor and a regular solution that implies a non-homogeneous Dirichlet condition on the domain boundary $\Gamma$ :

$$
\begin{gathered}
\mathbf{K}_{1}(x, y, z)=\left(\begin{array}{ccc}
1 & 0.5 & 0 \\
0.5 & 1 & 0.5 \\
0 & 0.5 & 1
\end{array}\right) \\
u_{1}(x, y, z)=1+\sin (\pi x) \sin \left(\pi\left(y+\frac{1}{2}\right)\right) \sin \left(\pi\left(z+\frac{1}{3}\right)\right)
\end{gathered}
$$

2. Test Case 2. We consider a smoothly variable permeability tensor and a regular solution that implies a non-homogeneous Dirichlet condition on the domain boundary $\Gamma$ :

$$
\begin{aligned}
& \mathbf{K}_{2}(x, y, z)=\left(\begin{array}{ccc}
y^{2}+z^{2}+1 & -x y & -x z \\
-x y & x^{2}+z^{2}+1 & -y z \\
-x z & -y z & x^{2}+y^{2}+1
\end{array}\right) \\
& u_{2}(x, y, z)=x^{3} y^{2} z+x \sin (2 \pi x z) \sin (2 \pi x y) \sin (2 \pi z)
\end{aligned}
$$

3. Test Case 3. We consider a constant, anisotropic permeability tensor and a regular solution on the domain, whose definition results from each of the considered meshes:

$$
\begin{gathered}
\mathbf{K}_{3}(x, y, z)=\left(\begin{array}{ccc}
1 & 0 & 0 \\
0 & 1 & 0 \\
0 & 0 & 10^{3}
\end{array}\right) \\
u_{3}(x, y, z)=\sin (2 \pi x) \sin (2 \pi y) \sin (2 \pi z)
\end{gathered}
$$

Since the meshes which are used for this test case (random meshes) have boundary vertices which are not located exactly on the boundary of the unit cube, the boundary conditions are non-homogeneous Dirichlet boundary conditions.

4. Test Case 4. The computational domain is given by $\Omega_{4}=P \backslash W$, where $P$ is the parallelepiped $]-15,15[\times]-15,15[\times]-7.5,7.5[$ and $W$ is a slanted circular cylinder with radius $r_{w}=0.1$. The axis of this well is a straight line located in the $x 0 z$ plane, passing by the origin, with an angle (in degrees) $\theta=-70^{\circ}$ with the $x$ axis, as shown in Figure 2.

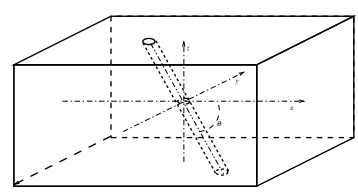

Fig. 2 The circular slanted well

We consider the constant permeability tensor, which is slightly anisotropic in the third coordinate direction, given by 


$$
\mathbf{K}_{4}=\left(\begin{array}{ccc}
1 & 0 & 0 \\
0 & 1 & 0 \\
0 & 0 & 0.2
\end{array}\right) .
$$

The exact solution $u_{4}(x, y, z)$ is detailed in [1]: once a stretching of the axes has been performed so as to obtain an isotropic problem, we seek an exact solution that is constant on the well boundary. The solution simulates the pressure field that would be obtained for the same infinite slanted circular well in an infinite domain for a given constant flow rate $q$ across any section of the well.

5. Test Case 5. The domain $\Omega=[0,1]^{3}$ is split into four subdomains $\Omega=\cup_{i=1}^{4} \Omega_{i}$, which are given by

$$
\begin{aligned}
& \Omega_{1}=\left\{(x, y, z) \in[0,1]^{3} \text { such that } y \leq 0.5, z \leq 0.5\right\} \\
& \Omega_{2}=\left\{(x, y, z) \in[0,1]^{3} \text { such that } y>0.5, z \leq 0.5\right\} \\
& \Omega_{3}=\left\{(x, y, z) \in[0,1]^{3} \text { such that } y>0.5, z>0.5\right\} \\
& \Omega_{4}=\left\{(x, y, z) \in[0,1]^{3} \text { such that } y \leq 0.5, z>0.5\right\}
\end{aligned}
$$

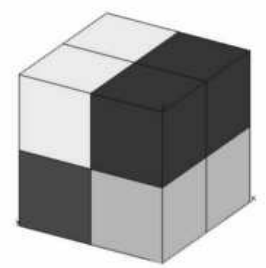

The permeability tensor and the exact solution are given by:

$$
\begin{aligned}
& \mathbf{K}_{5}(x, y, z)=\left(\begin{array}{ccc}
a_{x}^{i} & 0 & 0 \\
0 & a_{y}^{i} & 0 \\
0 & 0 & a_{z}^{i}
\end{array}\right) \quad \text { for }(x, y, z) \in \Omega_{i} \quad \text { with } \quad \begin{array}{c|c|c|c|c|c|}
i & 1 & 2 & 3 & 4 \\
\hline a_{x}^{i} & 1 & 1 & 1 & 1 \\
\hline a_{y}^{i} & 10 & 0.1 & 0.01 & 100 \\
\hline a_{z}^{i} & 0.01 & 100 & 10 & 0.1 \\
\hline \alpha_{i} & 0.1 & 10 & 100 & 0.01 \\
u_{5}(x, y, z)=\alpha_{i} \sin (2 \pi x) \sin (2 \pi y) \sin (2 \pi z)
\end{array}
\end{aligned}
$$

The permeability tensor $\mathbf{K}_{5}$ is discontinuous across the internal planes separating the unit cube in four subdomains and the exact solution $u_{5}$ is designed to be continuous and to ensure the conservation of the normal flux across such planes. Note that the homogeneous Dirichlet boundary condition is imposed in this test case.

\section{Linear solvers used for the linear system benchmark}

In order to access the different linear solver packages: UMFPACK $[17,18]$, DUNEISTL [?, 11], and PETSc [4, 5], all participants were asked to store their resulting

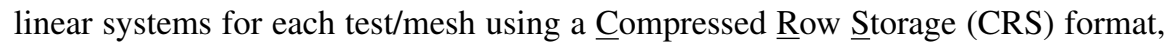
using an open source software package, which is available on line. All packages were installed on the 1 node Sun Fire X2270, equipped with 2 Quad-core processors (Intel, X5570, $2.93 \mathrm{GHz}$ ) and $24 \mathrm{~GB}$ memory (1333 MHz DDR3) and run sequentially.

Let us now briefly describe the available linear solvers and preconditioning methods. 
1 The direct solver library UMFPACK. Written in ANSI/ISO C, UMFPACK is a set of routines for solving unsymmetric sparse linear systems $A x=b$, using the Unsymmetric MultiFrontal method (see [17, 18] for details). For the benchmark, version 5.4.0 was used.

2 The Iterative Solver Template Library - DUNE-ISTL is a DUNE module $[?, 11]$, which provides $\mathrm{C}++$ programmed iterative solvers of linear systems stemming from finite element discretizations. The efficiency of the solvers is enhanced by taking into account the specific block recursive structure of matrices and vectors. For the benchmark version 2.0 has been used. The following solvers and preconditioning methods are used:

- Iterative solvers: Conjugate Gradient, BiCG-stab, GMRES;

- Preconditioning: Jacobi, ILU-0, ILU-n, $n=1, \ldots, 4$, Algebraic Multi Grid.

3 The Portable, Extensible Toolkit for Scientific Computation - PETSc [4, 5] is a suite of data structures and routines for the scalable (parallel) solution of scientific applications modeled by partial differential equations. The program code is written in ANSI C. For the benchmark, version 3.1-p5 was used. The following iterative solvers and preconditioning methods are used:

- Iterative solvers: Conjugate Gradient, BiCG-stab, GMRES;

- Preconditioning: Jacobi, ILU-n, $n=0, \ldots, 4$.

4 Condition number calculation. For the approximate calculation of the condition number of a given matrix, the Krylov-Schur method from the Scalable Library for Eigenvalue Problem Computations (SLEPc) package version 3.1-p4 [22] was used. SLEPc is written in ANSI C and built on top of PETSc.

5 CPU time measurement. The measurement of the CPU time spent for the solution process is based on the getrusage routines. The setup of the matrices (for the different solvers) is not included in the CPU time measurement in any case. The CPU time needed for the solution of the system with the iterative solvers (DUNE-ISTL and PETSc) is calculated by adding the time spent for building the preconditioner and the time spent in the linear solver. The CPU time with UMFPACK is not provided because the size of the matrices was too large for a direct solver in several cases.

\section{The participating schemes and teams}

Even though the benchmark is associated with the FVCA6 conference, the call for submission was by no means restricted to finite volume schemes, and, indeed, many types of schemes were submitted.

\section{Cell-centered schemes}

- MPFA-O: a Multi-Point Flux Approximation O-scheme programmed by the benchmark organizers for completeness purposes. 
- LS-FVM: The cell-centered finite volume method using least squares vertex reconstruction (diamond scheme), by Y. Coudière and G. Manzini [14].

Discontinuous Galerkin schemes

- CDG2: The Compact Discontinuous Galerkin 2 Scheme, R. Klöfkorn, [23].

- SWPG: Symmetric Weighted Interior Penalty Discontinuous Galerkin Scheme, by P. Bastian [6].

Discrete duality finite volume schemes

- CEVEDDFV-A: A version of the DDFV scheme with cell/vertex unknowns on general meshes, by B. Andreianov, F. Hubert and S. Krell [3].

- CeVeDDFV-B: CeVe-DDFV, a discrete duality scheme with cell/vertex unknowns, by Y. Coudière and C. Pierre [15].

- CeVeFE-DDFV: CeVeFE-DDFV, a discrete duality scheme with cell/vertex/face+edge unknowns, by Y. Coudière, F. Hubert and G. Manzini [13].

Finite element schemes

- FEM: Finite elements of order one (FEM1) and two (FEM2) provided by P. Bastian with the DUNE environment [7, 8].

- MELODIE, A linear finite element solver, by H. Amor, M. Bourgeois, and G. Mathieu [2].

Mixed or hybrid methods

- MFD-GEN: Mimetic finite difference method for generalized polyhedral meshes, by K. Lipnikov and G. Manzini [24].

- MFD-PLAIN: A mimetic finite difference method, by P. Bastian, O. Ippisch, and S. Marnach, [9].

- MFMFE: A multipoint flux mixed finite element method on general hexahedra, by M. F. Wheeler, G. Xue and I. Yotov [25].

- CHMFE: A composite hexahedral mixed finite element, by I. Ben Gharbia, J. Jaffré , N. Suresh Kumar and J. E. Roberts [10].

Gradient schemes

- SUSHI: The SUSHI scheme, by R. Eymard, T. Gallouët and R. Herbin, [19].

- VAG and VAGR: The VAG scheme, by R. Eymard, C. Guichard and R. Herbin, [20].

Nonlinear schemes The schemes are nonlinear in order to ensure the positivity of the scheme (that is, if the right hand side is positive then the solution is positive) or the discrete maximum principle (that is, if the linear system stems from the discretization of an elliptic equation satisfying the maximum principle, then its solution is also bounded by the bounds of the continuous system).

- FVMON: A monotone nonlinear finite volume method for diffusion equations on polyhedral meshes, by A. Danilov and Y. Vassilevski, [16].

The choice of categories that we considered above is neither exhaustive nor unique. In fact, most of these categories intersect: schemes are not so easy to classify, and some schemes are known to be identical in special cases and when using some special meshes. We refer to the above-cited papers for the details of the 
schemes and their implementation. Our purpose is to give here a synthesis of the results presented by the participants.

\section{Results obtained by the participants}

\subsection{Results provided by the participants}

The results obtained by the participants are presented in the contributed papers in several tables.

First table: it reports the data related to the size of the discrete problem produced by a numerical scheme and some information about the quality of the numerical approximation. In particular, the minimum and maximum values of the discrete solution at cell-centers are compared with the same kind of values for the exact solution, and an estimate of ngrad $\sim \int_{\Omega}\|\nabla u\|$ allows us to evaluate possible oscillations of the approximation.

\begin{tabular}{|l|l|}
\hline i & number of mesh \\
\hline nu & number of unknowns of the linear system \\
\hline nmat & number of non zero terms in the matrix \\
\hline umin & minimum value of the approximate solution at the cell centers \\
\hline uemin & minimum value of the exact solution at the cell centers \\
\hline umax & maximum value of the approximate solution at the cell centers \\
\hline uemax & maximum value of the exact solution at the cell centers \\
\hline normg & $L^{1}$ norm of the euclidean norm of the approximate gradient \\
\hline
\end{tabular}

Second table: it provides information about the accuracy of the schemes, which is measured for all the test cases versus nu, the number of unknowns, by the following quantities:

\begin{tabular}{|c|c|}
\hline i & number of mesh \\
\hline nu & number of unknowns of the linear system \\
\hline erl2 & $\begin{array}{l}\text { relative } L^{2} \text { norm of the error with respect to the } L^{2} \text { norm } \\
\text { of the exact solution. }\end{array}$ \\
\hline ratiol2 & $\begin{array}{l}\text { order of convergence of the } L^{2} \text { norm of the error on the } \\
\text { solution between mesh } i \text { and } i-1 \text {. }\end{array}$ \\
\hline ergrad & $\begin{array}{l}\text { relative } H^{1} \text { semi-norm of the error with respect to the } \\
H^{1} \text { semi-norm of the exact solution. }\end{array}$ \\
\hline ratiograd & $\begin{array}{l}\text { order of convergence of the } H^{1} \text { norm of the error on the } \\
\text { solution between mesh } i \text { and } i-1 \text {. }\end{array}$ \\
\hline ener & $\begin{array}{l}\text { relative energy norm of the error with respect to the en- } \\
\text { ergy norm of the exact solution. }\end{array}$ \\
\hline ratioener & $\begin{array}{l}\text { order of convergence of the energy norm of the error on } \\
\text { the solution between mesh } i \text { and } i-1 \text {. }\end{array}$ \\
\hline
\end{tabular}


where, denoting err the numerical error,

- the relative $L^{2}$ norm of the error is given by:

$$
\operatorname{erl} 2 \approx\left(\int_{\Omega}|e r r|^{2} / \int_{\Omega}|u|^{2}\right)^{\frac{1}{2}}
$$

- the relative $L^{2}$ norm of the gradient of the error is given by:

$$
\operatorname{ergrad} \approx\left(\int_{\Omega}|\nabla e r r|^{2} / \int_{\Omega}|\nabla u|^{2}\right)^{\frac{1}{2}}
$$

- the relative energy norm of the error is given by:

$$
\text { ener } \approx\left(\int_{\Omega} \mathbf{K} \nabla e r r \cdot \nabla e r r / \int_{\Omega} \mathbf{K} \nabla u \cdot \nabla u\right)^{\frac{1}{2}} .
$$

and the convergence rates are defined, for $i \geq 2$, by:

$$
\begin{aligned}
& \text { ratiol2(i) }=-3 \frac{\log (\operatorname{erl} 2(\mathrm{i}) / \operatorname{erl2}(i-1))}{\log (\mathrm{nu}(\mathrm{i}) / \mathrm{nu}(\mathrm{i}-1))} \text {; } \\
& \text { ratiograd(i) }=-3 \frac{\log (\operatorname{ergrad}(i) / \operatorname{ergrad}(i-1))}{\log (\mathrm{nu}(\mathrm{i}) / \mathrm{nu}(\mathrm{i}-1))} \text {; } \\
& \text { ratioener }(i)=-3 \frac{\log (\text { ener }(i) / \text { ener }(i-1))}{\log (\text { nu }(i) / \text { nu }(i-1))} \text {. }
\end{aligned}
$$

Matrices and right-hand sides were uploaded by the participants on the computer dedicated to the bench, in order to compare CPU time and memory.

\subsection{Comparisons}

- Maximum principle. For all test cases, we collect the values of $u_{\min }, u_{\max }$ for the coarsest and finest grids handled by the participants, in Tables 2, 3 and 4 (Test Case 1), 5 (Test Case 2), 6 (Test Case 3), 7 (Test Case 4) and 8 (Test Case 5). We colored in red (resp. purple) the values that are below (resp. above) the minimum value of the exact solution.

- Accuracy. In Figures 3-10, we report the log-log curves of the approximation errors measured by the benchmark participants for their numerical schemes. Each figure refers to a specific combination "test case + mesh family"; the upper leftmost plot reports er12, the upper right-most plot reports ergrad, the lower left-most plot reports normg, and the lower right-most plot reports ener. The convergence rates in these log-log plots are reflected by the slopes of the convergence curves. 
- Condition number. We report the condition number (see Section 3) of the matrices involved in the numerical discretizations of first two test cases in Tables 9, 10, 11 and 12 (Test Case 1) and in Table 13 (Test Cases 2). The condition numbers in each table are calculated for the first mesh and the two next mesh refinements. The eigensolver tolerance was set to $10^{-8}$ for all matrices.

- Cost of the resolution. The cost of the resolution of the linear systems is shown in Figures 11-18, where the $L^{2}$ error is plotted with respect to the CPU time and the used memory. The CPU time was measured for the linear system with the right hand side $b=A \mathbf{1}$, where $\mathbf{1}$ is the vector with all components equal to 1 . The stopping criterion for all the iterative methods is: residual $\leq 10^{-10}$. For the sake of simplicity, all methods, including conjugate gradient methods, have been applied to symmetric and non-symmetric matrices.

\section{Conclusion}

This paper proposes a comparison of sixteen numerical schemes (and variants) which were tested on a family of three-dimensional anisotropic diffusion problems. The tests presented here involve both a wide class of diffusion tensors (anisotropic and at time heterogeneous and/or discontinuous) and a wide class of conforming and non-conforming meshes with very general polyhedral cells.

The number of results which were obtained on this benchmark is impressive with respect to the difficulty of the exercise and the time constraint. In fact, additional results are available on the bench web site:

http: //www.latp.univ-mrs.fr/latp_numerique/?q=node/ 4.

and will be updated. The benchmark was found to be most useful to the participants to compare their schemes to reference solutions. The participation to the 3D benchmark was an opportunity for several participants to learn more about the efficient implementation of their schemes. Indeed, several variants of the schemes were thus developed. Last but not least, a user-friendly comparison platform was developed for this benchmark, which allows anyone to link to the solver and preconditioner of his choice; this possibility has already been used by other users than the 3D benchmark. The platform which was developed for the 3D benchmark should proof useful for further investigations on numerical schemes for various models.

\section{Acknowledgment}

The present paper is a synthesis of the work of several people:

- we first warmly thank all participants for their active collaboration in this benchmark, and for letting us use their results in this synthesis, 
- we are also very grateful to P. Bastian, C. Guichard, K. Lipnikov, R. Masson and S. Minjeaud for their help in the benchmark design.

This work was supported by GDR MOMAS, CNRS/PACEN and the ANR VFSitCom project. The work of the last author was also partially supported by the Italian MIUR through the program PRIN2008.

\section{References}

1. I. Aavatsmark and R. Klausen. Well index in reservoir simulation for slanted and slightly curved wells in 3d grids. SPE Journal, 8:41-48, 2003.

2. H. Amor, M. Bourgeois, and G. Mathieu. Benchmark 3d: a linear finite element solver. In these proceedings, 2011.

3. B. Andreianov, F. Hubert, and S. Krell. Benchmark 3d: a version of the ddfv scheme with cell/vertex unknowns on general meshes. In these proceedings, 2011.

4. S. Balay, J. Brown, K. Buschelman, W. D. Gropp, D. Kaushik, M. G. Knepley, L. C. McInnes, B. F. Smith, and H. Zhang. PETSc Web page, 2011. http://www.mcs.anl.gov/petsc.

5. S. Balay, W. D. Gropp, L. C. McInnes, and B. F. Smith. Efficient management of parallelism in object oriented numerical software libraries. In E. Arge, A. M. Bruaset, and H. P. Langtangen, editors, Modern Software Tools in Scientific Computing, pages 163-202. Birkhäuser Press, 1997.

6. P. Bastian. Benchmark 3d: Symmetric weighted interior penalty discontinuous galerkin scheme. In these proceedings, 2011.

7. P. Bastian, M. Blatt, A. Dedner, M. Engwer, R. Klöfkorn, M. Ohlberger, and O. Sander. A generic grid interface for parallel and adaptive scientific computing. part i: abstract framework. Computing, 82(2-3):103-119, 2008.

8. P. Bastian, M. Blatt, A. Dedner, M. Engwer, R. Klöfkorn, M. Ohlberger, and O. Sander. A generic grid interface for parallel and adaptive scientific computing. part i: part ii: implementation and tests in dune. Computing, 82(2-3):121-138, 2008.

9. P. Bastian, O. Ippisch, and S. Marnach. Benchmark 3d: A mimetic finite difference method. In these proceedings, 2011.

10. I. Ben Gharbia, J. Jaffré, S. N. Kumar, and J. E. Roberts. Benchmark 3d: a composite hexahedral mixed finite element. In these proceedings, 2011.

11. M. Blatt and P. Bastian. The iterative solver template library. In B. Kgstrm, E. Elmroth, J. Dongarra, and J. Wasniewski, editors, Applied Parallel Computing. State of the Art in Scientific Computing, volume 4699 of Lecture Notes in Computer Science, pages 666-675. Springer Berlin / Heidelberg, 2007.

12. M. Blatt and P. Bastian. DUNE-ISTL Web page, 2011. http://www.dune-project.org.

13. Y. Coudière, F. Hubert, and G. Manzini. Benchmark 3d: Cevefe-ddfv, a discrete duality scheme with cell/vertex/face+edge unknowns. In these proceedings, 2011.

14. Y. Coudière and G. Manzini. The cell-centered finite volume method using least squares vertex reconstruction (diamond scheme). In these proceedings, 2011.

15. Y. Coudière and C. Pierre. Benchmark 3d: Ceve-ddfv, a discrete duality scheme with cell/vertex unknowns. In these proceedings, 2011.

16. A. Danilov and Y. Vassilevski. Benchmark 3d: A monotone nonlinear finite volume method for diffusion equations on polyhedral meshes. In these proceedings, 2011.

17. T. A. Davis. Algorithm 832: UMFPACK V4.3 - an unsymmetric-pattern multifrontal method. ACM Trans. Math. Softw., 30(2):196-199, 2004.

18. T. A. Davis. UMFPACK Web page, 2011. http://www.cise.ufl.edu/research/sparse/umfpack/.

19. R. Eymard, T. Gallouët, and R. Herbin. Benchmark 3d: the sushi scheme. In these proceedings, 2011. 
20. R. Eymard, C. Guichard, and R. Herbin. Benchmark 3d: the vag scheme. In these proceedings, 2011.

21. R. Herbin and F. Hubert. Benchmark on discretization schemes for anisotropic diffusion problems on general grids. In Finite volumes for complex applications V, pages 659-692. ISTE, London, 2008.

22. V. Hernandez, J. E. Roman, and V. Vidal. SLEPc: A scalable and flexible toolkit for the solution of eigenvalue problems. ACM Transactions on Mathematical Software, 31(3):351362, Sept. 2005.

23. R. Klöfkorn. Benchmark 3d: The compact discontinuous galerkin 2 scheme. In these proceedings, 2011.

24. K. Lipnikov. and G. Manzini. Benchmark 3d: Mimetic finite difference method for generalized polyhedral meshes. In these proceedings, 2011.

25. M. F. Wheeler, G. Xue, and I. Yotov. Benchmark 3d: A multipoint flux mixed finite element method on general hexahedra. In these proceedings, 2011.

The paper is in final form and no similar paper has been or is being submitted elsewhere. 


\section{Tables and figures of results}

\begin{tabular}{||c||cc|cc||}
\hline Scheme & umin coarse umax coarse & \multicolumn{2}{|c||}{ umin fine } & umax fine \\
\hline CDG2K1 & $\mathbf{- 1 . 5 4 E - 0 2}$ & $\mathbf{2 . 0 1 7}$ & $\mathbf{- 6 . 6 3 E - 0 4}$ & $\mathbf{2 . 0 0 2}$ \\
\hline CDG2K2 & 0.00 & 1.999 & $0.00 \mathrm{E}+00$ & 1.999 \\
\hline CEVEDDFV-A & $0.706 \mathrm{E}-02$ & 1.992 & $0.140 \mathrm{E}-02$ & 1.999 \\
\hline CEVEDDFV-B & $1.34 \mathrm{E}-02$ & 1.99 & $1.30 \mathrm{E}-03$ & 2.00 \\
\hline CEVEFE-DDFV & $6.09 \mathrm{E}-03$ & 1.988 & $1.93 \mathrm{E}-03$ & 1.999 \\
\hline FEM1 & $8.34 \mathrm{E}-02$ & 1.932 & $6.35 \mathrm{E}-03$ & 1.990 \\
\hline FEM2 & $2.13 \mathrm{E}-02$ & 1.989 & $1.84 \mathrm{E}-03$ & 1.997 \\
\hline FVMON & 0.028 & 1.997 & 0.003 & 1.998 \\
\hline LS-FVM & $2.03 \mathrm{E}-02$ & 1.989 & $1.83 \mathrm{E}-03$ & 1.997 \\
\hline MELODIE & $7.69 \mathrm{E}-02$ & 1.935 & $6.19 \mathrm{E}-03$ & 1.991 \\
\hline MPFA-O & $-1.13 \mathrm{E}-02$ & 2.01 & $-1.46 \mathrm{E}-03$ & 2.00 \\
\hline MFD-PLAIN & $2.33 \mathrm{E}-03$ & 1.994 & $1.66 \mathrm{E}-03$ & 1.998 \\
\hline MFD-GEN & $2.26 \mathrm{E}-02$ & 1.986 & $1.75 \mathrm{E}-03$ & 1.997 \\
\hline SWPG-1 & $5.32 \mathrm{E}-02$ & 1.965 & $3.69 \mathrm{E}-03$ & 1.994 \\
\hline SWPG-2 & $2.11 \mathrm{E}-02$ & 1.989 & $1.84 \mathrm{E}-03$ & 1.997 \\
\hline SWPG-3 & $2.04 \mathrm{E}-02$ & 1.989 & $1.83 \mathrm{E}-03$ & 1.997 \\
\hline SWPG-4 & $2.03 \mathrm{E}-02$ & 1.989 & $1.83 \mathrm{E}-03$ & 1.997 \\
\hline SUSHI & $3.21 \mathrm{E}-02$ & 1.98 & $1.74 \mathrm{E}-03$ & 2.00 \\
\hline VAG & $6.77 \mathrm{E}-02$ & 1.94 & $4.62 \mathrm{E}-03$ & 1.99 \\
\hline VAGR & $5.77 \mathrm{E}-02$ & 1.95 & $3.63 \mathrm{E}-03$ & 1.99 \\
\hline & & & &
\end{tabular}

Table 2 Maximum principle for Test 1: mild anisotropy on tetrahedral meshes 


\begin{tabular}{||c||cc|cc||}
\hline Scheme & umin (coarse) & umax (coarse) & umin(fine) & umax(fine) \\
\hline CDG2LEGK1 & $\mathbf{- 2 . 9 5 E - 0 2}$ & $\mathbf{2 . 0 1 6}$ & $\mathbf{- 5 . 3 7 E - 0 4}$ & $\mathbf{2 . 0 0 0}$ \\
\hline CDG2LEGK2 & 0.00 & 1.997 & 0.00 & 1.999 \\
\hline CDG2TETK1 & $\mathbf{- 2 . 8 1 E - 0 2}$ & $\mathbf{2 . 0 1 2}$ & $\mathbf{- 4 . 6 5 E - 0 4}$ & 2.000 \\
\hline CDG2TETK2 & 0.00 & 1.995 & 0.00 & 1.999 \\
\hline CEVEDDFV-A & $2.28 \mathrm{E}-02$ & 1.989 & $3.82 \mathrm{E}-04$ & 2.000 \\
\hline CEVEDDFV-B & $7.16 \mathrm{E}-02$ & 1.94 & $4.61 \mathrm{E}-04$ & 2.00 \\
\hline CEVEFE-DDFV & $5.67 \mathrm{E}-02$ & 1.940 & $6.52 \mathrm{E}-04$ & 2.000 \\
\hline CHMFE & $\mathbf{- 0 . 0 3 2}$ & 1.94685 & $\mathbf{- 0 . 0 0 8}$ & $\mathbf{2 . 0 0 0 6 1}$ \\
\hline FEM1 & $1.77 \mathrm{E}-01$ & 1.786 & $2.94 \mathrm{E}-03$ & 1.996 \\
\hline FEM2 & $3.29 \mathrm{E}-02$ & 1.941 & $7.11 \mathrm{E}-04$ & 1.999 \\
\hline FVMON & 0.112 & 1.942 & 0.003 & 1.997 \\
\hline LS-FVM & $3.03 \mathrm{E}-02$ & 1.958 & $7.14 \mathrm{E}-04$ & 1.999 \\
\hline MELODIE & $1.34 \mathrm{E}-01$ & 1.833 & $2.04 \mathrm{E}-03$ & 1.997 \\
\hline MFD-GEN & $\mathbf{- 2 . 5 2 E - 0 2}$ & 1.973 & $2.71 \mathrm{E}-04$ & 1.999 \\
\hline MFD-PLAIN & $\mathbf{- 6 . 0 3 E - 0 1}$ & $\mathbf{2 . 1 0 0}$ & $1.65 \mathrm{E}-04$ & 2.000 \\
\hline MFMFE-NS & $\mathbf{- 1 . 2 6 E - 0 3}$ & $\mathbf{2 . 0 1}$ & $5.00 \mathrm{E}-05$ & 2.00 \\
\hline MFMFE-S & $4.66 \mathrm{E}-03$ & 1.97 & $7.49 \mathrm{E}-05$ & 2.00 \\
\hline MPFA-O & $\mathbf{- 3 . 7 6 E - 0 2}$ & $\mathbf{2 . 0 5}$ & $\mathbf{- 1 . 0 6 E - 0 3}$ & 2.00 \\
\hline SWPG-1 & $9.58 \mathrm{E}-02$ & 1.850 & $1.71 \mathrm{E}-03$ & 1.997 \\
\hline SWPG-2 & $3.12 \mathrm{E}-02$ & 1.944 & $7.11 \mathrm{E}-04$ & 1.999 \\
\hline SWPG-3 & $2.91 \mathrm{E}-02$ & 1.955 & $1.75 \mathrm{E}-03$ & 1.997 \\
\hline SWPG-4 & $3.02 \mathrm{E}-02$ & 1.958 & $1.75 \mathrm{E}-03$ & 1.997 \\
\hline SUSHI & $\mathbf{- 2 . 1 4 E - 0 3}$ & 1.91 & $8.51 \mathrm{E}-04$ & 2.00 \\
\hline VAG & $1.43 \mathrm{E}-01$ & 1.93 & $1.07 \mathrm{E}-03$ & 2.00 \\
\hline VAGR & $\mathbf{7 . 8 0 E - 0 2}$ & 1.96 & $\mathbf{- 2 . 6 4 E - 0 4}$ & 2.00 \\
\hline & & & & \\
\hline
\end{tabular}

Table 3 Maximum principle for Test 1: mild anisotropy on Kershaw meshes 


\begin{tabular}{||c||cc|cc||}
\hline Scheme & umin (coarse) & umax(coarse) & umin(fine) & umax(fine) \\
\hline CDG2K1 & 0.00 & 1.901 & $\mathbf{- 5 . 5 0 E - 0 4}$ & 2.000 \\
\hline CDG2K2 & $\mathbf{- 3 . 3 4 E - 0 2}$ & $\mathbf{2 . 0 5 0}$ & 0.000 & 1.999 \\
\hline CDG2LEGK1 & $\mathbf{- 7 . 9 4 E - 0 2}$ & $\mathbf{2 . 0 8 1}$ & $\mathbf{- 3 . 0 6 E - 0 4}$ & 2.000 \\
\hline CDG2LEGK2 & 0.00 & 1.998 & 0.00 & 1.999 \\
\hline CDG2TETK2 & 0.00 & $\mathbf{2 . 0 0 3}$ & 0.00 & 1.999 \\
\hline CEVEDDFV-A & $0.341 \mathrm{E}-01$ & 1.966 & $0.134 \mathrm{E}-03$ & 2.000 \\
\hline CEVEDDFV-B & $1.46 \mathrm{E}-01$ & 1.86 & $5.01 \mathrm{E}-04$ & 2.00 \\
\hline CEVEFE-DDFV & $8.58 \mathrm{E}-02$ & 1.903 & $2.88 \mathrm{E}-04$ & 2.000 \\
\hline FEM1 & $3.26 \mathrm{E}-01$ & 1.671 & $1.54 \mathrm{E}-03$ & 1.998 \\
\hline FVMON & 0.122 & 1.905 & 0.001 & 2.000 \\
\hline LS-FVM & $1.54 \mathrm{E}-01$ & 1.846 & $6.36 \mathrm{E}-04$ & 1.999 \\
\hline MFD-GEN & $2.91 \mathrm{E}-01$ & 1.880 & $2.15 \mathrm{E}-03$ & 1.999 \\
\hline MFD-PLAIN & $1.27 \mathrm{E}-01$ & 1.883 & $\mathbf{- 3 . 5 2 E - 0 3}$ & 2.004 \\
\hline SWPG-1 & $2.35 \mathrm{E}-01$ & 1.784 & $6.36 \mathrm{E}-04$ & 1.999 \\
\hline SWPG-2 & $1.82 \mathrm{E}-01$ & 1.812 & $6.37 \mathrm{E}-04$ & 1.999 \\
\hline SWPG-3 & $1.61 \mathrm{E}-01$ & 1.839 & $6.36 \mathrm{E}-04$ & 1.999 \\
\hline SWPG-4 & $1.55 \mathrm{E}-01$ & 1.845 & $6.36 \mathrm{E}-04$ & 1.999 \\
\hline SUSHI & $1.05 \mathrm{E}-01$ & 1.87 & $3.83 \mathrm{E}-04$ & 2.00 \\
\hline VAG & $\mathbf{- 1 . 9 5}$ & $\mathbf{2 . 5 0}$ & $\mathbf{- 3 . 0 6 E - 0 2}$ & 2.03 \\
\hline VAGR & $\mathbf{- 9 . 8 1 E - 0 2}$ & $\mathbf{2 . 0 8 E + 0 0}$ & $\mathbf{- 4 . 3 3 E - 0 3}$ & 2.00 \\
\hline
\end{tabular}

Table 4 Maximum principle for Test 1: mild anisotropy on Checkerboard meshes

\begin{tabular}{||c||cc|cc||}
\hline Scheme & umin (coarse) & umax(coarse) & umin(fine) & umax(fine) \\
\hline CEVEDDFV-A & -.856 & 1.044 & -.862 & 1.049 \\
\hline CEVEDDFV-B & $-8.53 \mathrm{E}-01$ & $9.85 \mathrm{E}-01$ & $-8.58 \mathrm{E}-01$ & 1.03 \\
\hline CEVEFE-DDFV & $-8.55 \mathrm{E}-01$ & 1.014 & $-8.60 \mathrm{E}-01$ & 1.040 \\
\hline FVMON & -0.854 & 1.002 & -0.858 & 1.034 \\
\hline LS-FVM & $-8.42 \mathrm{E}-01$ & 0.978 & $-8.57 \mathrm{E}-01$ & 1.033 \\
\hline MFD-GEN & $\mathbf{- 0 . 8 7 3}$ & 0.832 & $\mathbf{- 0 . 8 9 0}$ & 0.963 \\
\hline MPFA-O & $\mathbf{- 9 . 2 3 E - 0 1}$ & 1.07 & $-8.63 \mathrm{E}-01$ & $\mathbf{1 . 0 5}$ \\
\hline SUSHI & $-8.22 \mathrm{E}-01$ & $9.82 \mathrm{E}-01$ & $-8.55 \mathrm{E}-01$ & 1.03 \\
\hline VAG & $\mathbf{- 9 . 4 9 E - 0 1}$ & $\mathbf{1 . 2 3}$ & $-8.53 \mathrm{E}-01$ & $\mathbf{1 . 0 5}$ \\
\hline VAGR & $\mathbf{- 8 . 7 3 E - 0 1}$ & $\mathbf{1 . 1 0 E}+\mathbf{0 0}$ & $-8.53 \mathrm{E}-01$ & 1.04 \\
\hline
\end{tabular}

Table 5 Maximum principle for Test 2: heterogeneous anisotropy on Prismatic meshes 


\begin{tabular}{||c||cc|cc||}
\hline Scheme & umin(coarse) & umax(coarse) & umin(fine) & umax(fine) \\
\hline CDG2LEGK1 & $\mathbf{- 1 . 1 4 3}$ & $\mathbf{1 . 2 4 4}$ & $\mathbf{- 1 . 0 0 9}$ & 1.000 \\
\hline CDG2LEGK2 & $\mathbf{- 1 . 0 1 5}$ & $\mathbf{1 . 0 3 4}$ & $-1.00 \mathrm{E}+00$ & 1.00 \\
\hline CDG2TETK1 & $\mathbf{- 1 . 2 6 1}$ & $\mathbf{1 . 1 6 7}$ & $\mathbf{- 1 . 0 0 8}$ & $\mathbf{1 . 0 0 2}$ \\
\hline CDG2TETK2 & $\mathbf{- 1 . 2 3 8}$ & $\mathbf{1 . 2 9 5}$ & -1.000 & 1.000 \\
\hline CEVEDDFV-A & $\mathbf{- . 2 0 2 E + 0 1}$ & $\mathbf{1 . 9 6 9}$ & $\mathbf{- . 1 0 1 E + 0 1}$ & $\mathbf{1 . 0 1 4}$ \\
\hline CEVEDDFV-B & $\mathbf{- 1 . 5 8}$ & $\mathbf{1 . 5 4}$ & $\mathbf{- 1 . 0 1}$ & $\mathbf{1 . 0 1}$ \\
\hline CEVEFE-DDFV & $\mathbf{- 4 . 2 5 E + 0 1}$ & $\mathbf{4 9 . 1 6 9}$ & $\mathbf{- 2 . 6 7}$ & $\mathbf{2 . 7 2 5}$ \\
\hline FEM1 & $-3.73 \mathrm{E}-01$ & 0.313 & $-9.90 \mathrm{E}-01$ & 0.989 \\
\hline FEM2 & $-7.48 \mathrm{E}-01$ & 0.679 & $-9.96 \mathrm{E}-01$ & 0.996 \\
\hline FVMON & -0.905 & 0.759 & -0.989 & $\mathbf{1 . 0 0 1}$ \\
\hline LS-FVM & $-7.56 \mathrm{E}-01$ & 0.711 & $-9.96 \mathrm{E}-01$ & 0.996 \\
\hline MELODIE & -0.665 & 0.685 & -0.988 & 0.991 \\
\hline MFD-GEN & $\mathbf{- 1 . 2 6 8}$ & $\mathbf{1 . 4 3 0}$ & $\mathbf{- 1 . 0 2 7}$ & $\mathbf{1 . 0 2 1}$ \\
\hline MFD-PLAIN & $\mathbf{- 1 . 0 2 E + 0 0}$ & $\mathbf{1 . 0 4 5}$ & -1.00 & 1.000 \\
\hline MFMFE-S & $\mathbf{- 6 . 2 0}$ & $\mathbf{5 . 7 5}$ & $\mathbf{- 1 . 0 6}$ & $\mathbf{1 . 0 4}$ \\
\hline MPFA-O & $\mathbf{- 9 . 7 9}$ & $\mathbf{1 . 2 2 E}+\mathbf{0 1}$ & $\mathbf{- 2 . 6 1 E + 0 1}$ & $\mathbf{2 . 4 4 E + 0 1}$ \\
\hline SUSHI & $-7.51 \mathrm{E}-01$ & $7.58 \mathrm{E}-01$ & $-9.90 \mathrm{E}-01$ & $9.89 \mathrm{E}-01$ \\
\hline SWPG-1 & $-4.34 \mathrm{E}-01$ & 0.355 & $-9.90 \mathrm{E}-01$ & 0.989 \\
\hline SWPG-2 & $-7.50 \mathrm{E}-01$ & 0.676 & $-9.96 \mathrm{E}-01$ & 0.996 \\
\hline SWPG-3 & $-7.53 \mathrm{E}-01$ & 0.684 & $-9.96 \mathrm{E}-01$ & 0.996 \\
\hline SWPG-4 & $-\mathbf{7 . 5 9 E - 0 1}$ & 0.691 & $-9.85 \mathrm{E}-01$ & 0.982 \\
\hline VAG & $\mathbf{- 1 . 3 1}$ & $\mathbf{1 . 5 0}$ & -1.00 & 1.00 \\
\hline VAGR & $\mathbf{- 1 . 5 1}$ & $\mathbf{1 . 6 8 E + 0 0}$ & $\mathbf{- 1 . 0 1}$ & $\mathbf{1 . 0 1}$ \\
\hline & & & & \\
\hline
\end{tabular}

Table 6 Maximum principle for Test 3: flow on random meshes 


\begin{tabular}{|c|c|c|c|c|}
\hline Scheme & umin(coarse) & umax (coarse) & umin(fine) & umax(fine) \\
\hline CDG2LEGK1 & 0.00 & 5.406 & 0.00 & 5.410 \\
\hline CDG2LEGK2 & 0.00 & 5.408 & 0.00 & 5.411 \\
\hline CDG2TETK1 & 0.00 & 5.406 & 0.00 & 5.410 \\
\hline CDG2TETK2 & $-5.92 \mathrm{E}-03$ & 5.414 & 0.00 & 5.414 \\
\hline CEVEDDFV-A & $-.438 \mathrm{E}-01$ & 5.415 & $\begin{array}{l}-.198 \mathrm{E}-02 \\
\end{array}$ & 5.415 \\
\hline CEVEDDFV-B & $4.85 \mathrm{E}-01$ & 5.32 & $5.80 \mathrm{E}-02$ & 5.36 \\
\hline CEVEFE-DDFV & $3.83 \mathrm{E}-01$ & 5.317 & \begin{tabular}{|l|}
$5.66 \mathrm{E}-02$ \\
\end{tabular} & 5.361 \\
\hline FEM1 & $3.73 \mathrm{E}-01$ & 5.317 & $5.66 \mathrm{E}-02$ & 5.361 \\
\hline FEM2 & $4.12 \mathrm{E}-01$ & 5.317 & \begin{tabular}{|l|}
$5.65 \mathrm{E}-02$ \\
\end{tabular} & 5.361 \\
\hline FVMON & 0.518 & 5.318 & 0.059 & 5.361 \\
\hline LS-FVM & $4.57 \mathrm{E}-01$ & 5.317 & $5.75 \mathrm{E}-02$ & 5.361 \\
\hline MELODIE & 0.189 & 5.360 & 0.029 & 5.39 \\
\hline MFD-GEN & $5.37 \mathrm{E}-01$ & 5.317 & $5.91 \mathrm{E}-02$ & 5.361 \\
\hline MFD-PLAIN & $5.74 \mathrm{E}-01$ & 5.317 & $5.91 \mathrm{E}-02$ & 5.361 \\
\hline MPFA-O & $4.36 \mathrm{E}-01$ & 5.39 & \begin{tabular}{|l|}
$-1.49 \mathrm{E}-03$ \\
\end{tabular} & 5.40 \\
\hline SUSHI & $4.26 \mathrm{E}-01$ & 5.32 & $5.78 \mathrm{E}-02$ & 5.36 \\
\hline SWPG-1 & $3.52 \mathrm{E}-01$ & 5.316 & \begin{tabular}{|l|}
$5.55 \mathrm{E}-02$ \\
\end{tabular} & 5.361 \\
\hline SWPG-2 & $4.13 \mathrm{E}-01$ & 5.317 & $5.65 \mathrm{E}-02$ & 5.361 \\
\hline SWPG-3 & $4.15 \mathrm{E}-01$ & 5.317 & $5.65 \mathrm{E}-02$ & 5.361 \\
\hline SWPG-4 & $4.14 \mathrm{E}-01$ & 5.317 & 8.99E-02 & 5.339 \\
\hline VAG & $3.89 \mathrm{E}-01$ & 5.32 & 5.69E-02 & 5.36 \\
\hline VAGR & $3.89 \mathrm{E}-01$ & 5.32 & \begin{tabular}{|l|}
$5.69 \mathrm{E}-02$ \\
\end{tabular} & 5.36 \\
\hline
\end{tabular}

Table 7 Maximum principle for Test 4: the flow around the well

\begin{tabular}{||c||cc|cc||}
\hline Scheme & umin(coarse) & umax(coarse) & umin(fine) & umax(fine) \\
\hline CDG2LEGK1 & -12.747 & 12.747 & $\mathbf{- 1 0 0 . 2 4 1}$ & $\mathbf{1 0 0 . 2 4 1}$ \\
\hline CDG2LEGK2 & -94.815 & 94.815 & -99.987 & 99.987 \\
\hline CEVEFE-DDFV & $-6.34 \mathrm{E}+01$ & $\mathbf{6 4 . 4 6 2}$ & $\mathbf{- 1 . 0 2 E + 0 2}$ & $\mathbf{1 0 2 . 3 9 4}$ \\
\hline FEM1 & $-1.87 \mathrm{E}-02$ & 0.019 & $-9.78 \mathrm{E}+01$ & 97.772 \\
\hline FVMON & $\mathbf{- 2 4 6 . 7 3 6}$ & $\mathbf{2 4 6 . 7 3 6}$ & -99.719 & 99.719 \\
\hline LS-FVM & $-1.00 \mathrm{E}+02$ & $1.00 \mathrm{E}+02$ & $-9.86 \mathrm{E}+01$ & 98.562 \\
\hline MFD-GEN & $\mathbf{- 1 . 6 6 E + 0 2}$ & $\mathbf{1 . 6 6 E}+\mathbf{0 2}$ & $-9.95 \mathrm{E}+01$ & $9.95 \mathrm{E}+01$ \\
\hline MFD-PLAIN & $\mathbf{- 2 . 5 1 E + 0 2}$ & $\mathbf{2 5 0 . 8 0 8}$ & $-9.89 \mathrm{E}+01$ & 98.887 \\
\hline SWPG-1 & $\mathbf{- 5 . 4 6 E + 0 1}$ & $\mathbf{5 4 . 5 9 4}$ & $-9.78 \mathrm{E}+01$ & 97.780 \\
\hline SWPG-2 & $\mathbf{- 1 . 1 8 E + 0 2}$ & $\mathbf{1 1 8 . 3 2 5}$ & $-9.86 \mathrm{E}+01$ & 98.563 \\
\hline SWPG-3 & $\mathbf{- 1 . 0 5 E + 0 2}$ & $\mathbf{1 0 4 . 5 8 6}$ & $-9.86 \mathrm{E}+01$ & 98.562 \\
\hline SUSHI & $\mathbf{- 2 . 4 9 E + 0 2}$ & $\mathbf{2 . 4 9 E}+\mathbf{0 2}$ & $-9.89 \mathrm{E}+01$ & $9.89 \mathrm{E}+01$ \\
\hline VAG & $\mathbf{- 7 . 6 5 E + 0 2}$ & $\mathbf{7 . 6 5 E}+\mathbf{0 2}$ & $-9.93 \mathrm{E}+01$ & $9.93 \mathrm{E}+01$ \\
\hline VAGR & $\mathbf{- 7 . 3 9 E + 0 2}$ & $\mathbf{7 . 3 9 E + 0 2}$ & $-1.00 \mathrm{E}+02$ & $1.00 \mathrm{E}+02$ \\
\hline & & & &
\end{tabular}

Table 8 Maximum principle for Test 5: discontinuous anisotropy 


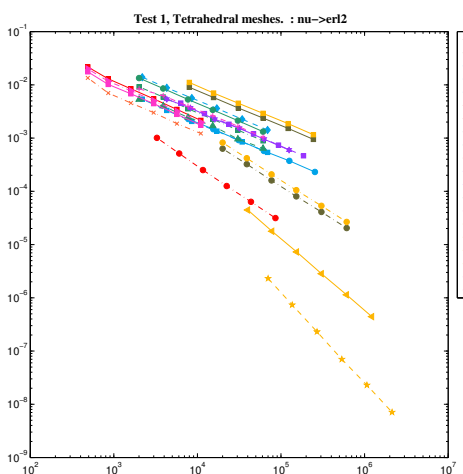

(a) erl2

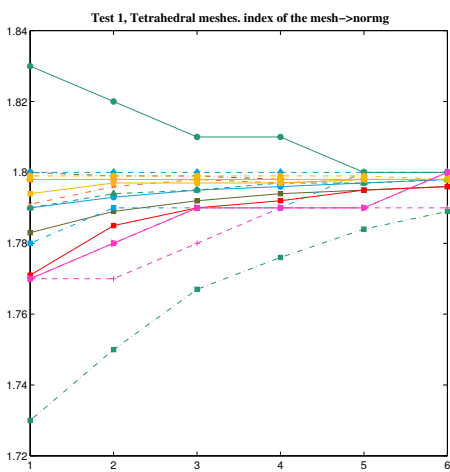

(c) normg

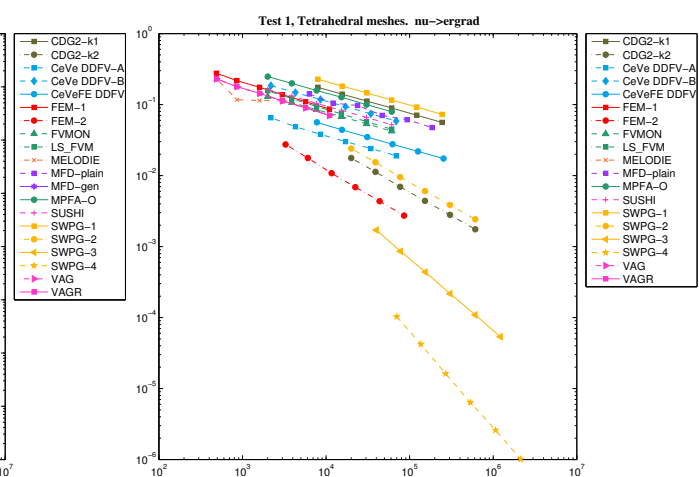

(b) ergrad

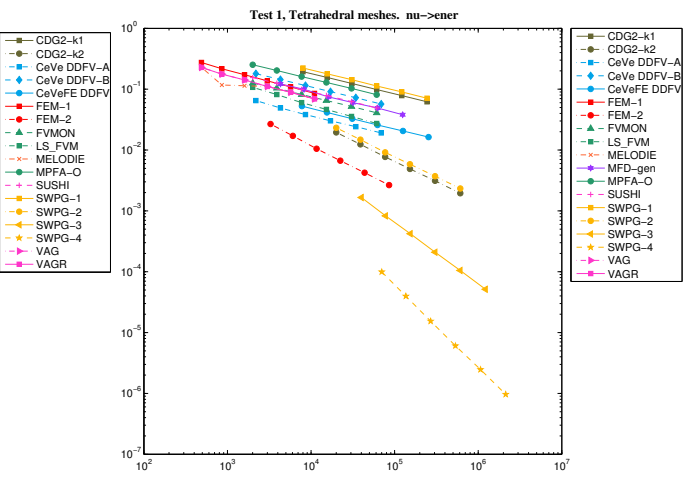

(d) ener

Fig. 3 Accuracy of the schemes for Test Case 1 on tetrahedral meshes. Plot $(a)$ shows the relative $L^{2}$-norm of the error, plot $(b)$ shows the relative $H^{1}$-seminorm of the error, plot $(c)$ the $L^{1}$-norm of the numerical gradient, and $(d)$ the energy norm of the error. 


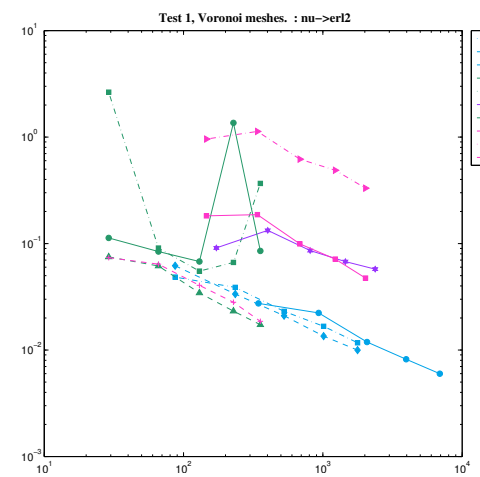

(a) erl2

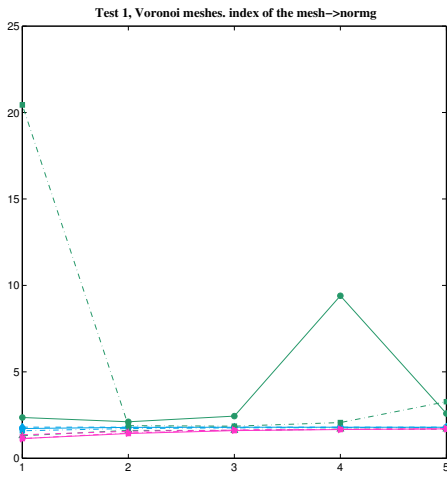

(c) normg

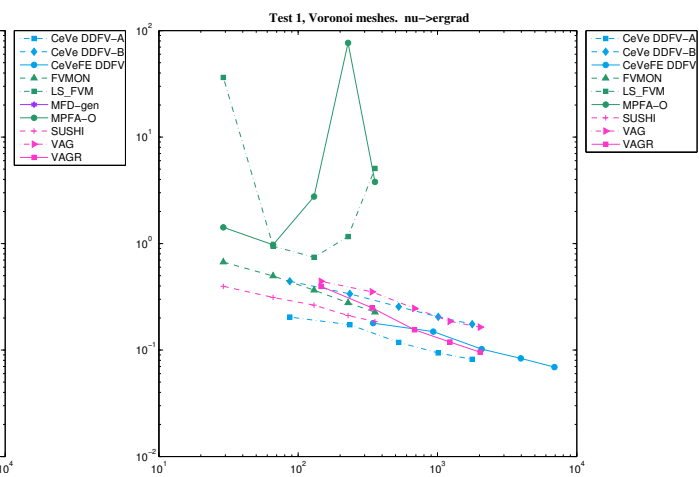

(b) ergrad

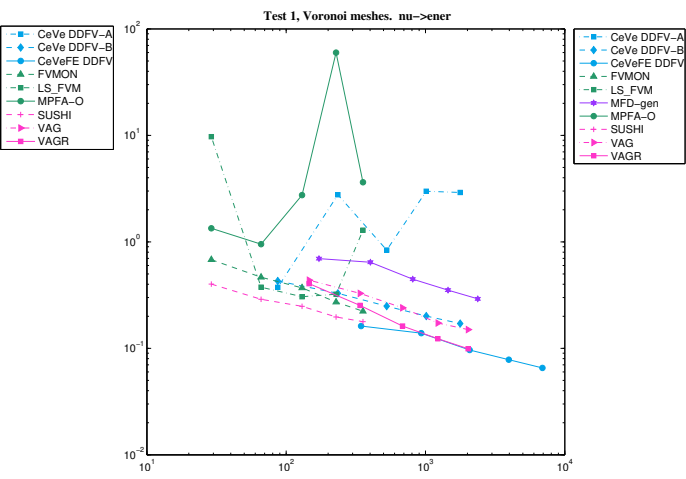

(d) ener

Fig. 4 Accuracy of the schemes for Test Case 1 on Voronoi meshes. Plot $(a)$ shows the relative $L^{2}$-norm of the error, plot $(b)$ shows the relative $H^{1}$-seminorm of the error, plot $(c)$ the $L^{1}$-norm of the numerical gradient, and $(d)$ the energy norm of the error. 


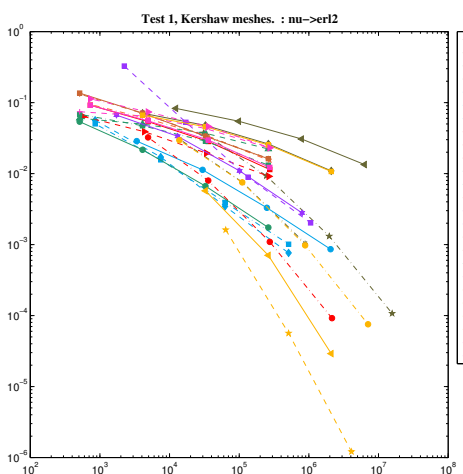

(a) $\operatorname{erl} 2$

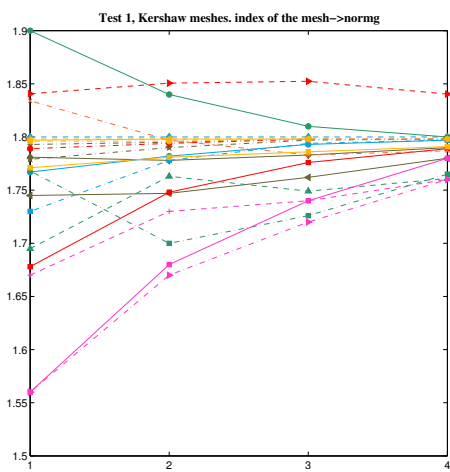

(c) normg

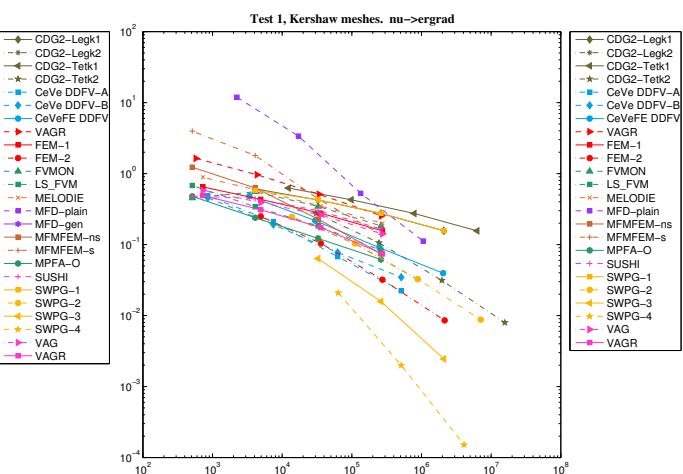

(b) ergrad

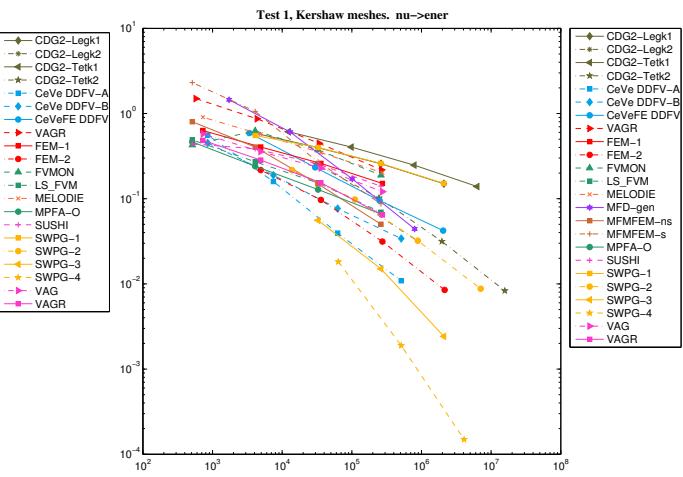

(d) ener

Fig. 5 Accuracy of the schemes for Test Case 1 on Kershaw meshes. Plot $(a)$ shows the relative $L^{2}$-norm of the error, plot $(b)$ shows the relative $H^{1}$-seminorm of the error, plot $(c)$ the $L^{1}$-norm of the numerical gradient, and $(d)$ the energy norm of the error. 


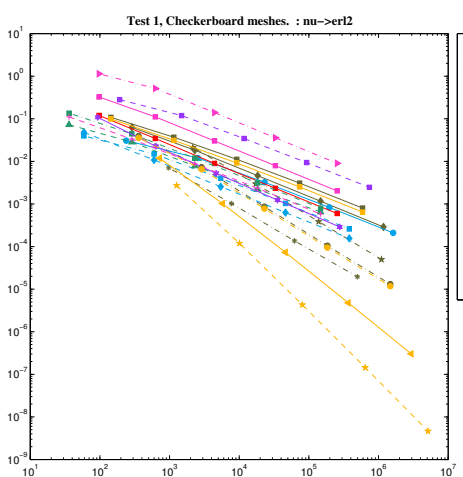

(a) erl2

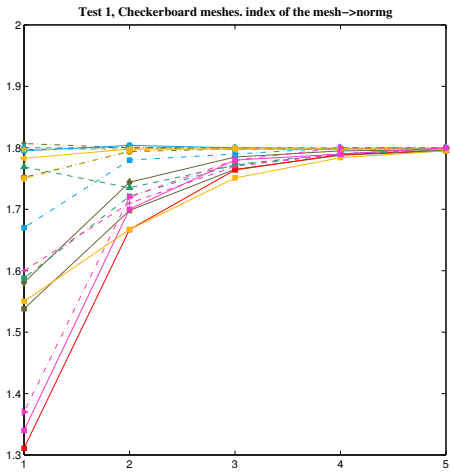

(c) normg

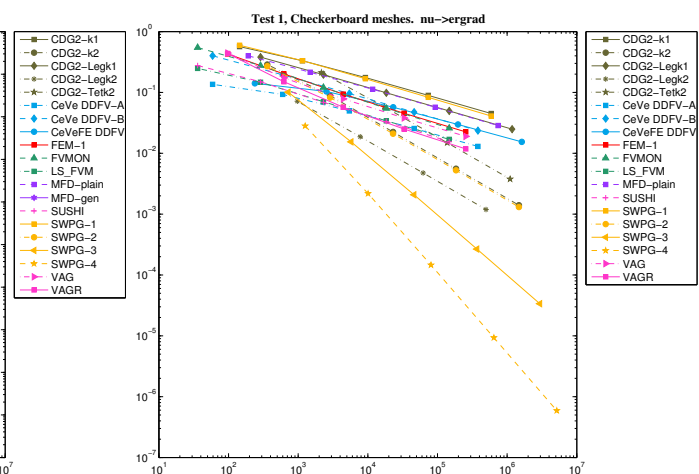

(b) ergrad

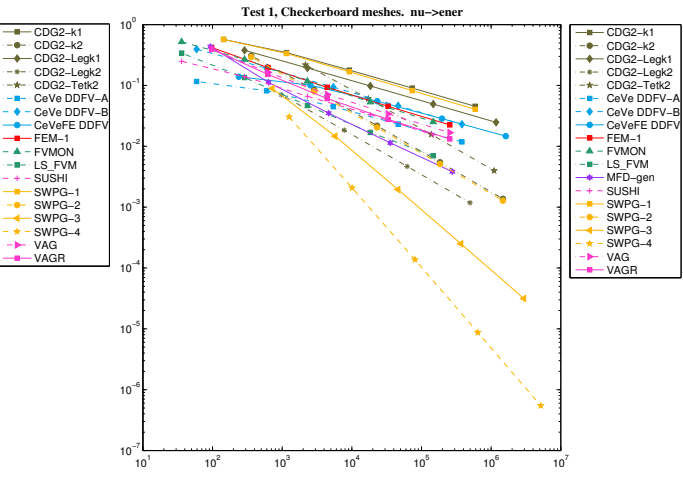

(d) ener

Fig. 6 Accuracy of the schemes for Test Case 1 on Checkerboard meshes. Plot $(a)$ shows the relative $L^{2}$-norm of the error, plot $(b)$ shows the relative $H^{1}$-seminorm of the error, plot $(c)$ the $L^{1}$-norm of the numerical gradient, and $(d)$ the energy norm of the error. 


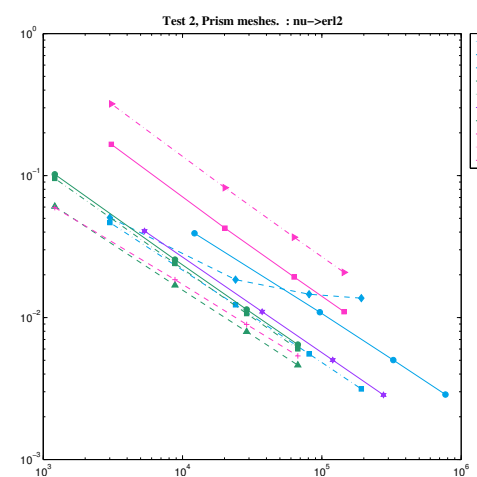

(a) $\operatorname{erl} 2$

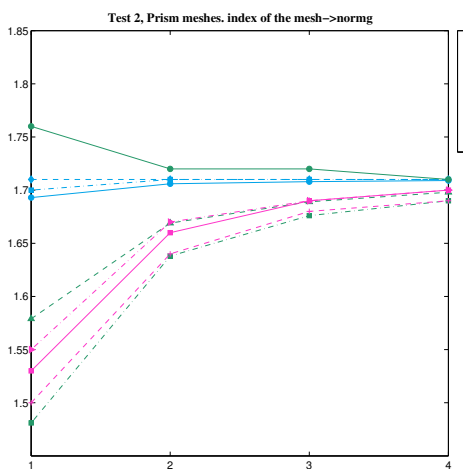

(c) normg

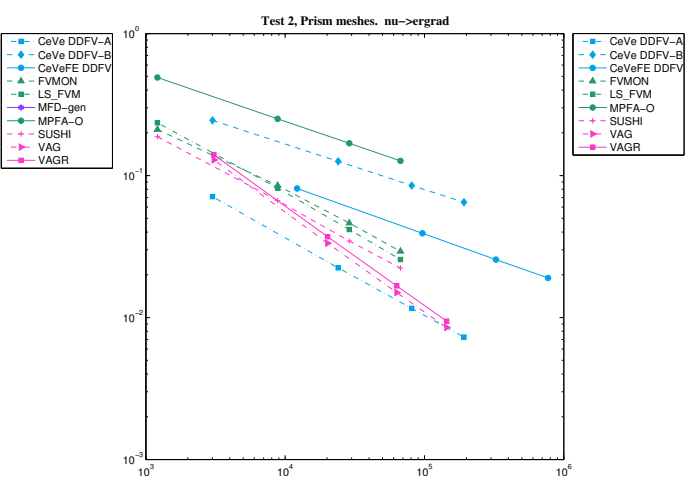

(b) ergrad

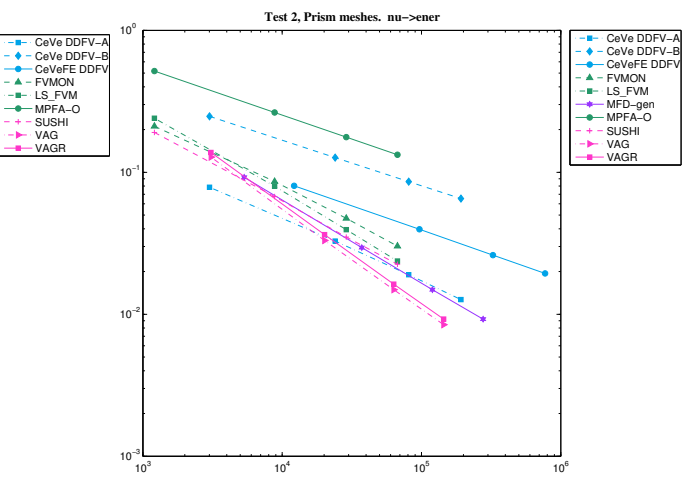

(d) ener

Fig. 7 Accuracy of the schemes for Test Case 2. Plot $(a)$ shows the relative $L^{2}$-norm of the error, plot $(b)$ shows the relative $H^{1}$-seminorm of the error, plot $(c)$ the $L^{1}$-norm of the numerical gradient, and $(d)$ the energy norm of the error. 


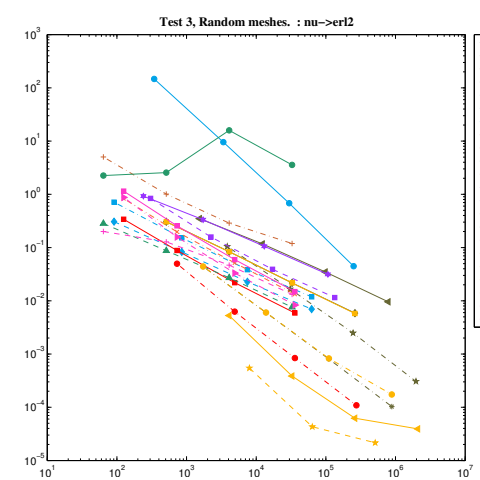

(a) erl2

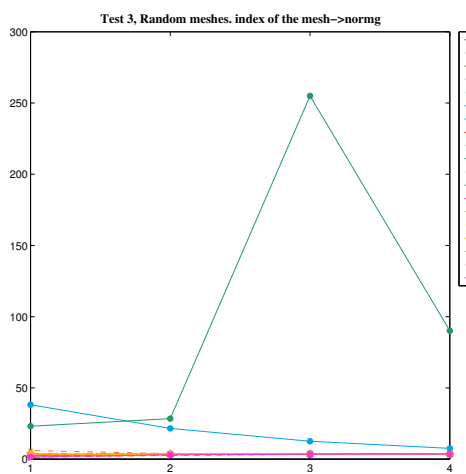

(c) normg

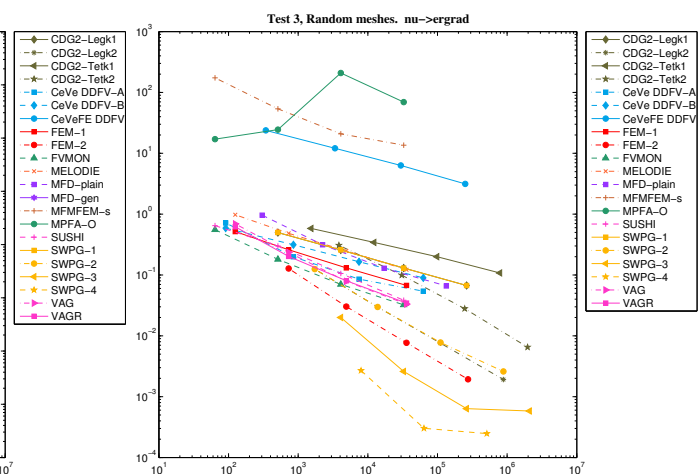

(b) ergrad

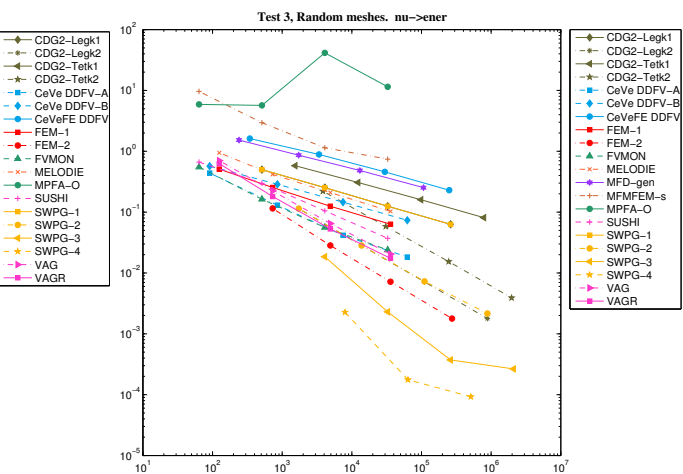

(d) ener

Fig. 8 Accuracy of the schemes for Test Case 3. Plot $(a)$ shows the relative $L^{2}$-norm of the error, plot $(b)$ shows the relative $H^{1}$-seminorm of the error, plot $(c)$ the $L^{1}$-norm of the numerical gradient, and $(d)$ the energy norm of the error. 


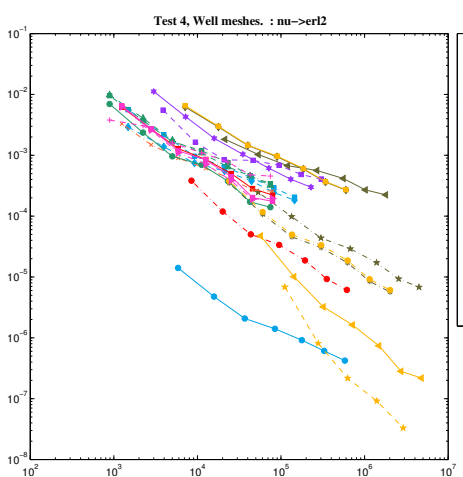

(a) $\operatorname{erl} 2$

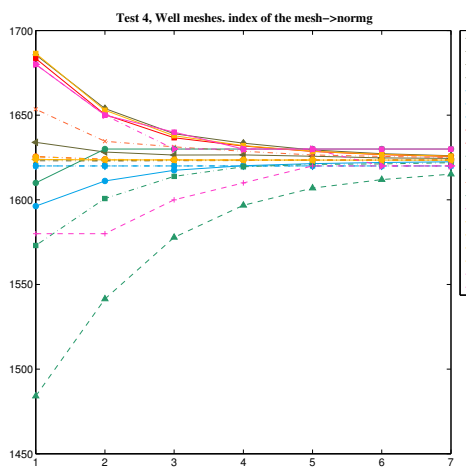

(c) normg

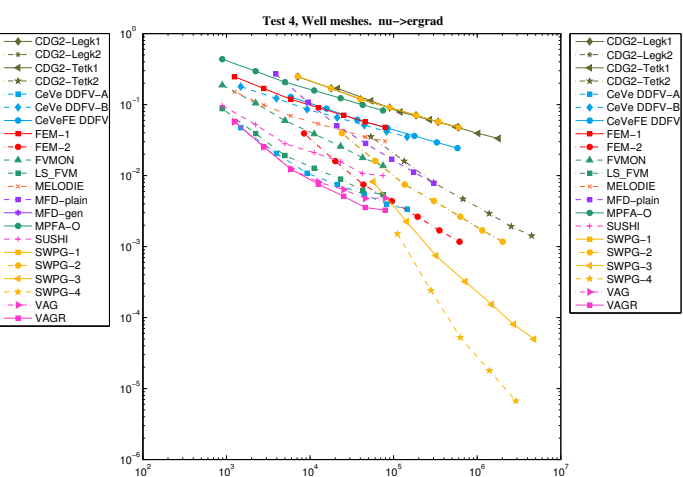

(b) ergrad

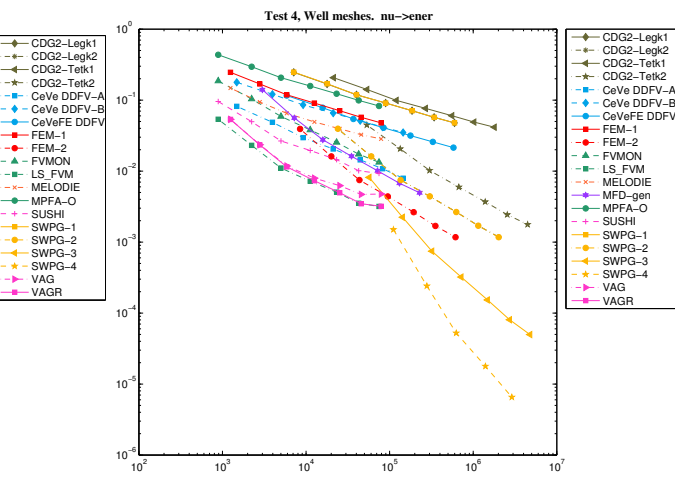

(d) ener

Fig. 9 Accuracy of the schemes for Test Case 4. Plot $(a)$ shows the relative $L^{2}$-norm of the error, plot $(b)$ shows the relative $H^{1}$-seminorm of the error, plot $(c)$ the $L^{1}$-norm of the numerical gradient, and $(d)$ the energy norm of the error. 


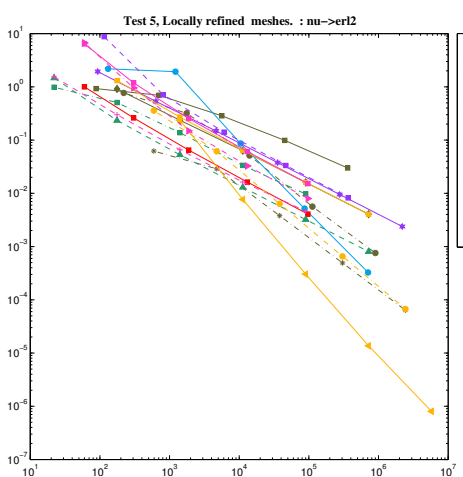

(a) erl2

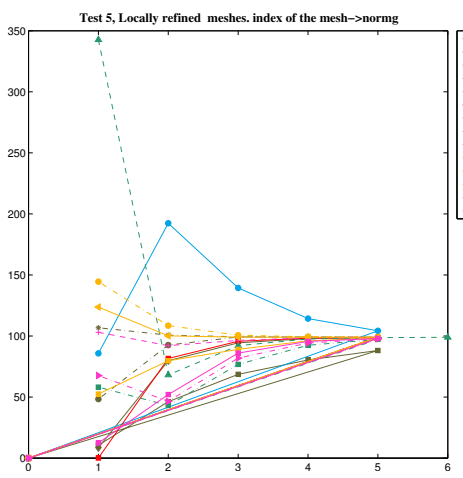

(c) normg

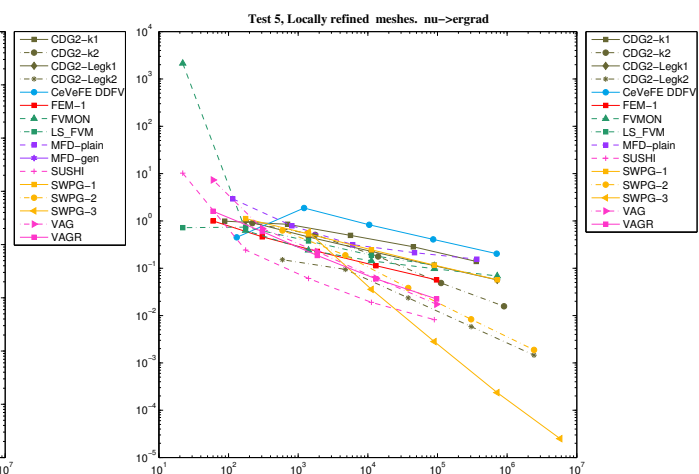

(b) ergrad

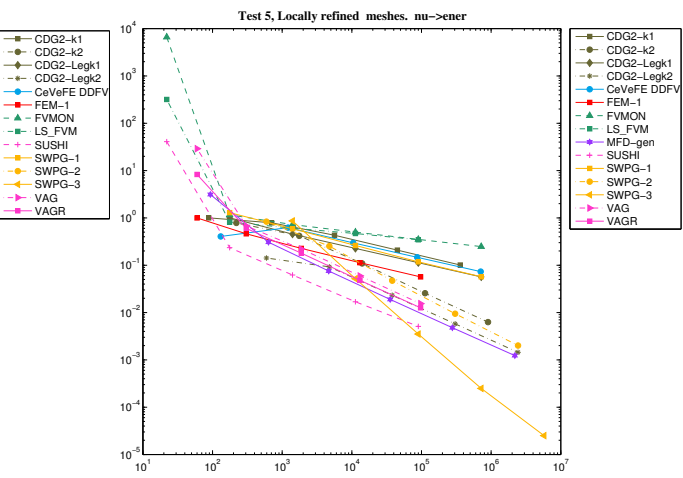

(d) ener

Fig. 10 Accuracy of the schemes for Test Case 5. Plot $(a)$ shows the relative $L^{2}$-norm of the error, plot $(b)$ shows the relative $H^{1}$-seminorm of the error, plot $(c)$ the $L^{1}$-norm of the numerical gradient, and $(d)$ the energy norm of the error. 


\begin{tabular}{||c||ccc||}
\hline \multicolumn{1}{||}{ Scheme } & \multicolumn{3}{c||}{ Condition number } \\
\hline & $\mathrm{i}=1$ & $\mathrm{i}=2$ & $\mathrm{i}=3$ \\
\hline CDG2-k1 & $6.96 \mathrm{E}+03$ & $8.36 \mathrm{E}+03$ & $1.81 \mathrm{E}+04$ \\
CDG2-k2 & $2.37 \mathrm{E}+04$ & $2.80 \mathrm{E}+04$ & $5.98 \mathrm{E}+04$ \\
CeVe DDFV-A & $2.67 \mathrm{E}+02$ & $3.72 \mathrm{E}+02$ & $9.15 \mathrm{E}+02$ \\
CeVe DDFV-B & $2.75 \mathrm{E}+02$ & $3.91 \mathrm{E}+02$ & $9.34 \mathrm{E}+02$ \\
CeVeFE DDFV & $9.36 \mathrm{E}+02$ & $1.31 \mathrm{E}+03$ & $3.04 \mathrm{E}+03$ \\
FEM-1 & $2.68 \mathrm{E}+01$ & $4.79 \mathrm{E}+01$ & $7.39 \mathrm{E}+01$ \\
FEM-2 & $2.24 \mathrm{E}+02$ & $3.66 \mathrm{E}+02$ & $5.96 \mathrm{E}+02$ \\
FVMON & $8.90 \mathrm{E}+02$ & $9.56 \mathrm{E}+02$ & $2.09 \mathrm{E}+03$ \\
LS-FVM & $2.80 \mathrm{E}+02$ & $3.91 \mathrm{E}+02$ & $9.62 \mathrm{E}+02$ \\
MELODIE & $1.18 \mathrm{E}+02$ & $6.04 \mathrm{E}+01$ & $1.65 \mathrm{E}+02$ \\
MFD-gen & $1.34 \mathrm{E}+03$ & $1.46 \mathrm{E}+03$ & $3.32 \mathrm{E}+03$ \\
MFD-plain & $1.46 \mathrm{E}+03$ & $2.47 \mathrm{E}+03$ & $3.87 \mathrm{E}+03$ \\
MPFA-O & $3.28 \mathrm{E}+01$ & $5.01 \mathrm{E}+01$ & $8.64 \mathrm{E}+01$ \\
SUSHI & $8.34 \mathrm{E}+02$ & $1.32 \mathrm{E}+03$ & $2.67 \mathrm{E}+03$ \\
SWPG-1 & $1.29 \mathrm{E}+04$ & $1.53 \mathrm{E}+04$ & $3.33 \mathrm{E}+04$ \\
SWPG-2 & $6.37 \mathrm{E}+04$ & $7.42 \mathrm{E}+04$ & $1.60 \mathrm{E}+05$ \\
SWPG-3 & $1.82 \mathrm{E}+05$ & $2.13 \mathrm{E}+05$ & $4.64 \mathrm{E}+05$ \\
SWPG-4 & $4.15 \mathrm{E}+05$ & $4.86 \mathrm{E}+05$ & $1.06 \mathrm{E}+06$ \\
VAG & $2.68 \mathrm{E}+01$ & $4.79 \mathrm{E}+01$ & $7.39 \mathrm{E}+01$ \\
VAGR & $2.68 \mathrm{E}+01$ & $4.79 \mathrm{E}+01$ & $7.39 \mathrm{E}+01$ \\
\hline
\end{tabular}

Table 9 Matrix condition numbers for the first three meshes in the solution of Test Case 1 using Tetrahedral meshes.

\begin{tabular}{||c||ccc||}
\hline \multicolumn{1}{|c||}{ Scheme } & \multicolumn{3}{c||}{ Condition number } \\
\hline & $\mathrm{i}=1$ & $\mathrm{i}=2$ & $\mathrm{i}=3$ \\
\hline CeVe DDFV-A & $9.51 \mathrm{E}+01$ & $1.24 \mathrm{E}+02$ & $3.33 \mathrm{E}+02$ \\
CeVe DDFV-B & $5.07 \mathrm{E}+01$ & $9.40 \mathrm{E}+01$ & $2.05 \mathrm{E}+02$ \\
CeVeFE DDFV & $1.05 \mathrm{E}+03$ & $2.00 \mathrm{E}+05$ & $1.98 \mathrm{E}+05$ \\
FVMON & $1.03 \mathrm{E}+01$ & $9.97 \mathrm{E}+00$ & $1.58 \mathrm{E}+02$ \\
MPFA-O & $5.78 \mathrm{E}+01$ & $8.32 \mathrm{E}+01$ & - \\
SUSHI & $1.45 \mathrm{E}+01$ & $1.12 \mathrm{E}+01$ & $3.07 \mathrm{E}+01$ \\
VAG & $6.51 \mathrm{E}+01$ & $7.95 \mathrm{E}+02$ & $4.19 \mathrm{E}+02$ \\
VAGR & $1.82 \mathrm{E}+01$ & $3.68 \mathrm{E}+01$ & $8.36 \mathrm{E}+01$ \\
\hline
\end{tabular}

Table 10 Matrix condition numbers for the first three meshes in the solution of Test Case 1 using Voronoi meshes. 


\begin{tabular}{||c||ccc||}
\hline \multicolumn{1}{||c||}{ Scheme } & \multicolumn{3}{c||}{ Condition number } \\
\hline CDG2-Legk1 & $3.06 \mathrm{E}+04$ & $1.84 \mathrm{E}+05$ & $1.01 \mathrm{E}+06$ \\
CDG2-Legk2 & $1.99 \mathrm{E}+05$ & $1.04 \mathrm{E}+06$ & - \\
CDG2-Tetk1 & $1.41 \mathrm{E}+05$ & $6.14 \mathrm{E}+05$ & $2.62 \mathrm{E}+06$ \\
CDG2-Tetk2 & $5.22 \mathrm{E}+05$ & $2.17 \mathrm{E}+06$ & - \\
CeVe DDFV-A & $6.67 \mathrm{E}+02$ & $3.25 \mathrm{E}+03$ & $1.54 \mathrm{E}+04$ \\
CeVe DDFV-B & $7.08 \mathrm{E}+02$ & $3.85 \mathrm{E}+03$ & $1.84 \mathrm{E}+04$ \\
CeVeFE DDFV & $3.80 \mathrm{E}+03$ & $1.99 \mathrm{E}+04$ & $9.77 \mathrm{E}+04$ \\
FEM-1 & $1.54 \mathrm{E}+02$ & $1.12 \mathrm{E}+03$ & $7.50 \mathrm{E}+03$ \\
FEM-2 & $2.55 \mathrm{E}+03$ & $1.55 \mathrm{E}+04$ & $9.58 \mathrm{E}+04$ \\
FVMON & $3.31 \mathrm{E}+02$ & $2.07 \mathrm{E}+03$ & $8.65 \mathrm{E}+03$ \\
LS-FVM & $2.86 \mathrm{E}+02$ & $1.37 \mathrm{E}+03$ & $9.76 \mathrm{E}+03$ \\
MELODIE & $5.27 \mathrm{E}+02$ & $2.27 \mathrm{E}+03$ & $1.28 \mathrm{E}+04$ \\
MFD-gen & $2.10 \mathrm{E}+03$ & $7.53 \mathrm{E}+03$ & $4.17 \mathrm{E}+04$ \\
MFD-plain & $2.65 \mathrm{E}+03$ & $1.29 \mathrm{E}+04$ & $7.47 \mathrm{E}+04$ \\
MFMFEM-ns & $1.12 \mathrm{E}+02$ & $9.19 \mathrm{E}+02$ & $6.88 \mathrm{E}+03$ \\
MFMFEM-s & $2.02 \mathrm{E}+02$ & $1.25 \mathrm{E}+03$ & $7.77 \mathrm{E}+03$ \\
MPFA-O & $8.19 \mathrm{E}+01$ & $8.12 \mathrm{E}+02$ & $5.31 \mathrm{E}+02$ \\
SUSHI & $1.08 \mathrm{E}+03$ & $2.51 \mathrm{E}+03$ & $1.47 \mathrm{E}+04$ \\
VAG & $1.80 \mathrm{E}+02$ & $1.08 \mathrm{E}+03$ & $7.28 \mathrm{E}+03$ \\
VAGR & $1.76 \mathrm{E}+02$ & $1.19 \mathrm{E}+03$ & $7.62 \mathrm{E}+03$ \\
\hline
\end{tabular}

Table 11 Matrix condition numbers for the first three meshes in the solution of Test Case 1 using Kershaw meshes.

\begin{tabular}{||c||ccc||}
\hline \multicolumn{1}{|c||}{ Scheme } & \multicolumn{3}{c||}{ Condition number } \\
\hline & $\mathrm{i}=1$ & $\mathrm{i}=2$ & $\mathrm{i}=3$ \\
\hline CeVe DDFV-A & $1.52 \mathrm{E}+01$ & $5.20 \mathrm{E}+01$ & $2.00 \mathrm{E}+02$ \\
CeVe DDFV-B & $9.82 \mathrm{E}+00$ & $3.39 \mathrm{E}+01$ & $1.29 \mathrm{E}+02$ \\
CeVeFE DDFV & $5.72 \mathrm{E}+01$ & $2.31 \mathrm{E}+02$ & $9.29 \mathrm{E}+02$ \\
FVMON & $8.00 \mathrm{E}+00$ & $2.62 \mathrm{E}+01$ & $9.44 \mathrm{E}+01$ \\
MFD-plain & $3.06 \mathrm{E}+01$ & $1.71 \mathrm{E}+02$ & $8.09 \mathrm{E}+02$ \\
SUSHI & $6.96 \mathrm{E}+00$ & $2.47 \mathrm{E}+01$ & $9.83 \mathrm{E}+01$ \\
SWPG-1 & - & $1.50 \mathrm{E}+02$ & $6.55 \mathrm{E}+02$ \\
VAG & $3.41 \mathrm{E}+00$ & $2.01 \mathrm{E}+01$ & $1.46 \mathrm{E}+02$ \\
VAGR & $2.62 \mathrm{E}+00$ & $1.83 \mathrm{E}+01$ & $1.42 \mathrm{E}+02$ \\
\hline
\end{tabular}

Table 12 Matrix condition numbers for the first three meshes in the solution of Test Case 1 using Checkerboard meshes. 


\begin{tabular}{||c||ccc||}
\hline \multicolumn{1}{|c||}{ Scheme } & \multicolumn{3}{c||}{ Condition number } \\
\hline & $\mathrm{i}=1$ & $\mathrm{i}=2$ & $\mathrm{i}=3$ \\
\hline CeVe DDFV-A & $2.08 \mathrm{E}+02$ & $1.03 \mathrm{E}+03$ & $2.51 \mathrm{E}+03$ \\
CeVe DDFV-B & $1.31 \mathrm{E}+02$ & $7.16 \mathrm{E}+02$ & $1.79 \mathrm{E}+03$ \\
CeVeFE DDFV & $1.17 \mathrm{E}+03$ & $5.65 \mathrm{E}+03$ & $1.35 \mathrm{E}+04$ \\
FVMON & $7.23 \mathrm{E}+01$ & $3.49 \mathrm{E}+02$ & $8.41 \mathrm{E}+02$ \\
LS-FVM & $9.77 \mathrm{E}+01$ & $5.13 \mathrm{E}+02$ & $1.29 \mathrm{E}+03$ \\
MPFA-O & $8.65 \mathrm{E}+01$ & $4.90 \mathrm{E}+02$ & $1.27 \mathrm{E}+03$ \\
SUSHI & $1.02 \mathrm{E}+02$ & $5.26 \mathrm{E}+02$ & $1.30 \mathrm{E}+03$ \\
VAG & $7.44 \mathrm{E}+01$ & $4.48 \mathrm{E}+02$ & $1.42 \mathrm{E}+03$ \\
VAGR & $9.57 \mathrm{E}+01$ & $5.41 \mathrm{E}+02$ & $1.42 \mathrm{E}+03$ \\
\hline
\end{tabular}

Table 13 Matrix condition numbers for the first three meshes in the solution of Test Case 2 using Prismatic meshes. 


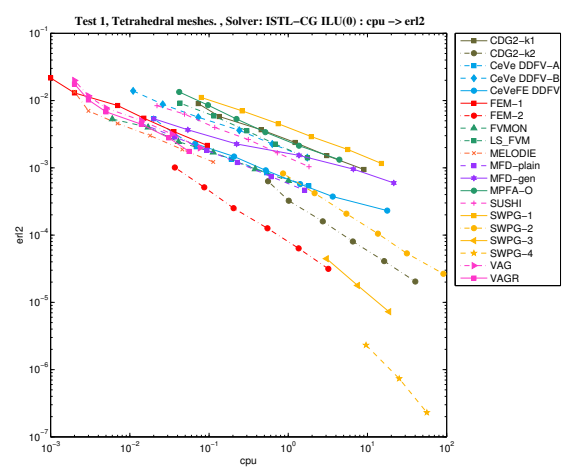

(a) ISTL-CG ILU(0): cpu $\rightarrow$ rer12

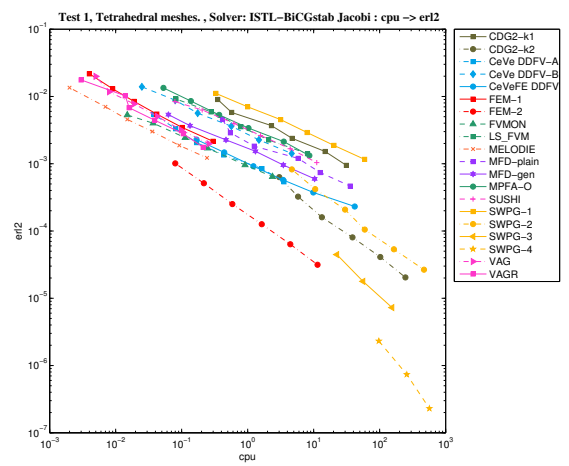

(c) ISTL-BiCGstab Jacobi: cpu $\rightarrow$ erl2

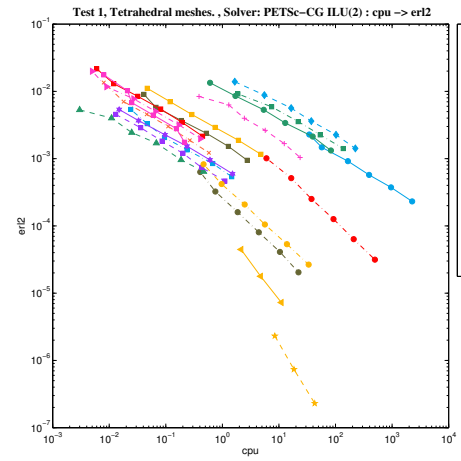

(e) PETSc-CG ILU(2): cpu $\rightarrow$ erl2



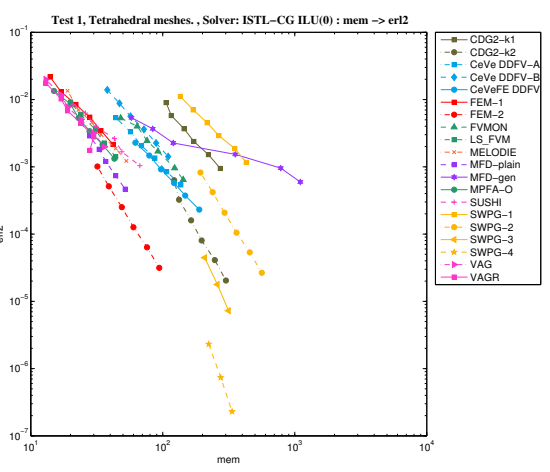

(b) ISTL-CG ILU(0):memory $\rightarrow$ erl2

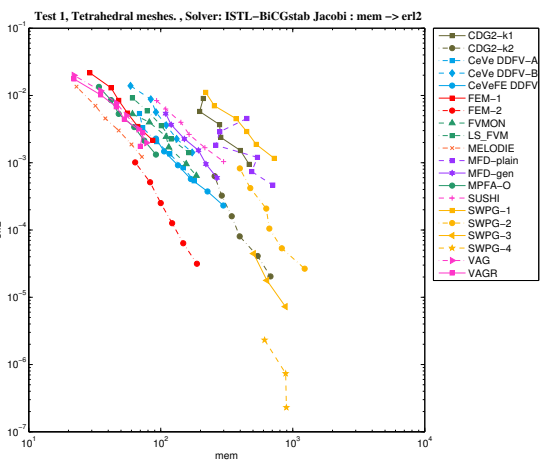

(d) ISTL-BiCGstab Jacobi:memory $\rightarrow$ erl2

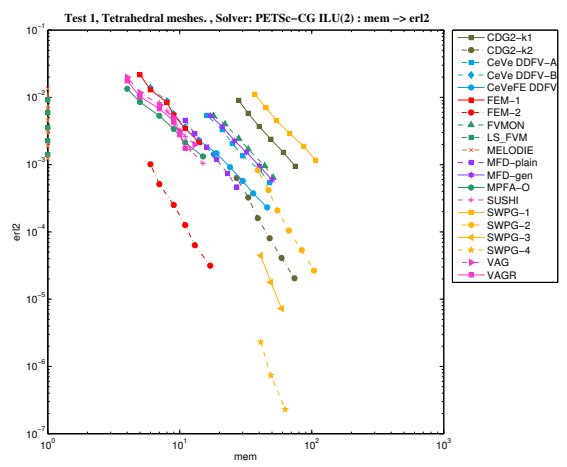

(f) PETSc-CG ILU(2): memory $\rightarrow$ erl2

Fig. 11 Test 1-Tetrahedral meshes. 


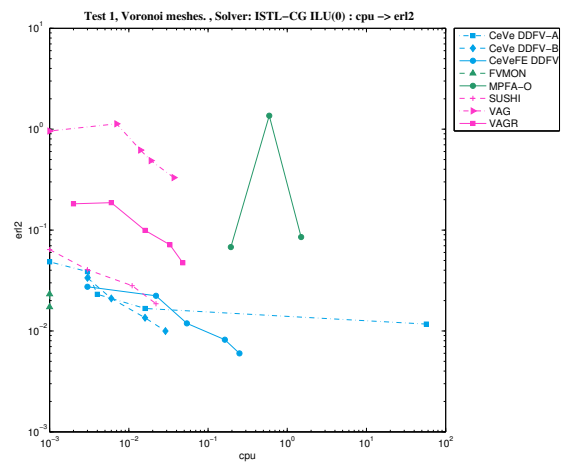

(a) ISTL-CG ILU(0): cpu $\rightarrow$ erl2

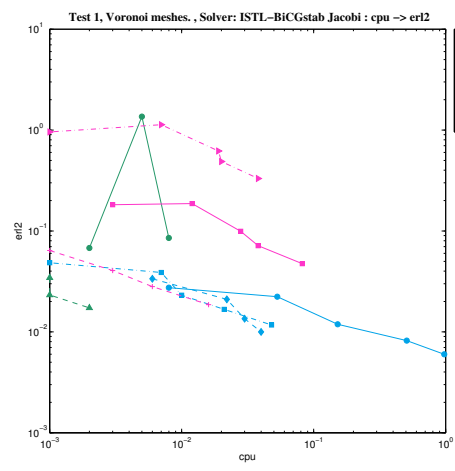

(c) ISTL-BiCGstab Jacobi: cpu $\rightarrow$ erl2

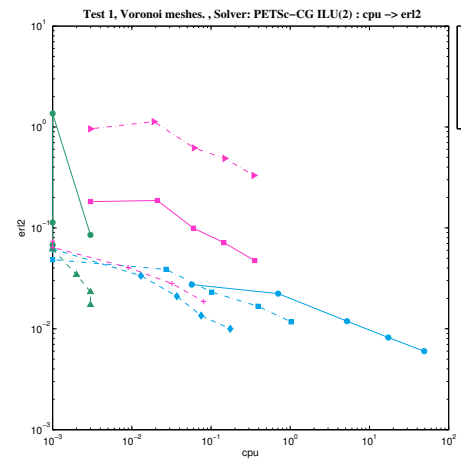

(e) PETSc-CG ILU(2): cpu $\rightarrow$ erl2

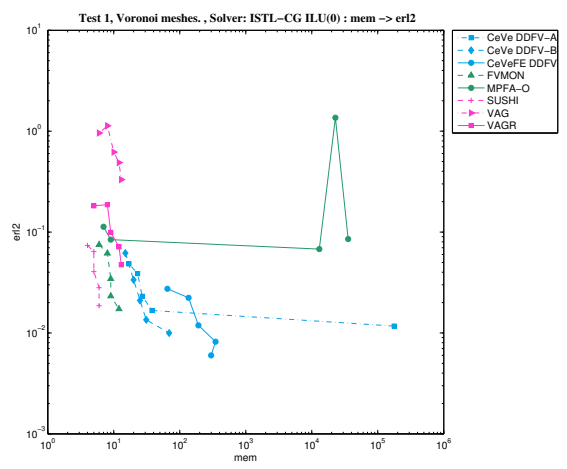

(b) ISTL-CG ILU(0):memory $\rightarrow$ erl2

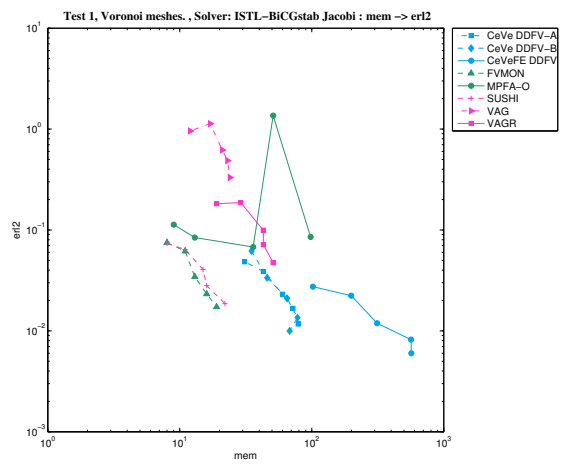

(d) ISTL-BiCGstab Jacobi:memory $\rightarrow$ erl2

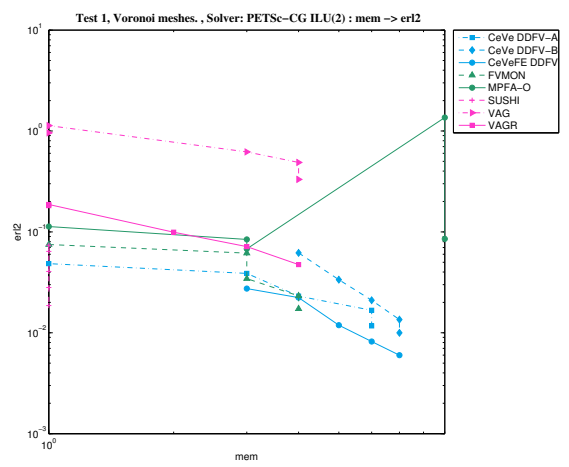

(f) PETSc-CG ILU(2): memory $\rightarrow$ erl2

Fig. 12 Test 1-Voronoi meshes. 


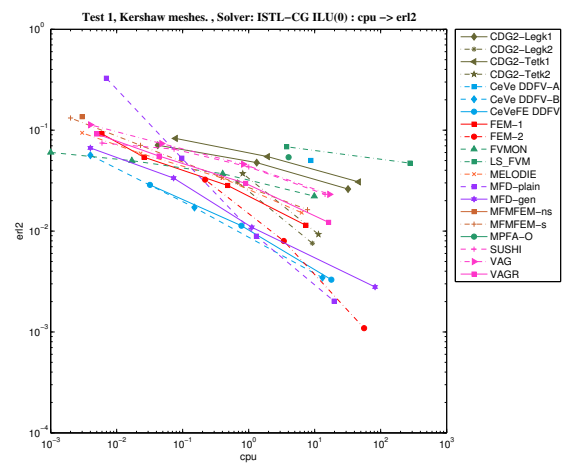

(a) ISTL-CG ILU(0): cpu $\rightarrow$ rer12

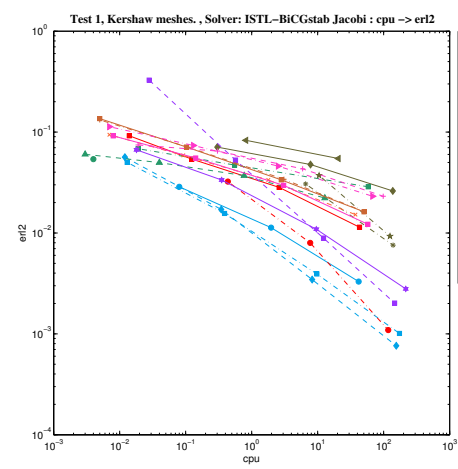

(c) ISTL-BiCGstab Jacobi: cpu $\rightarrow$ erl2

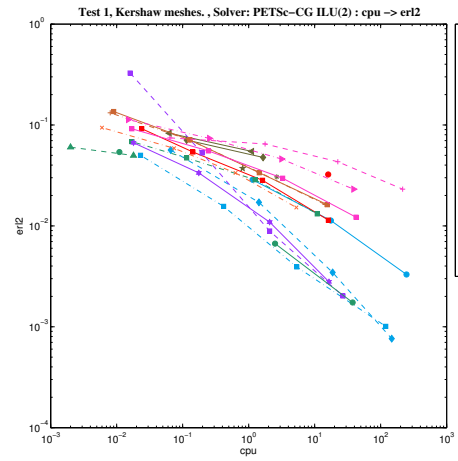

(e) PETSc-CG ILU(2): cpu $\rightarrow$ erl2



(b) ISTL-CG ILU(0):memory $\rightarrow$ erl2

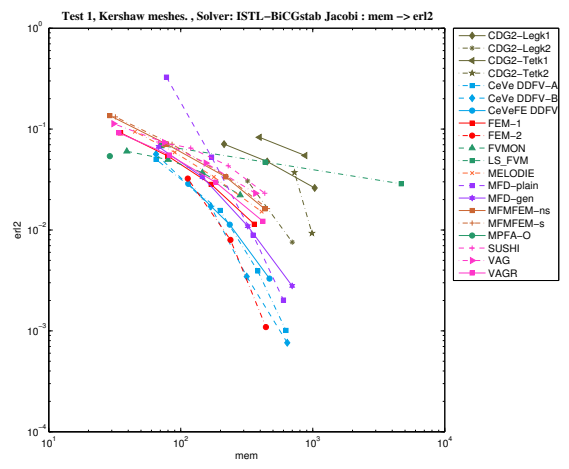

(d) ISTL-BiCGstab Jacobi:memory $\rightarrow$ erl2

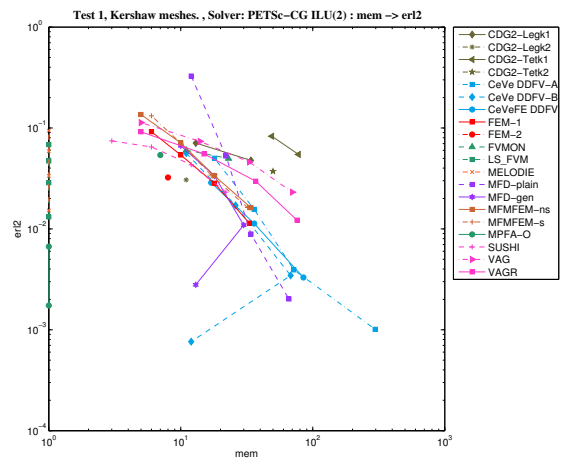

(f) PETSc-CG ILU(2): memory $\rightarrow$ erl2

Fig. 13 Test 1-Kershaw meshes. 


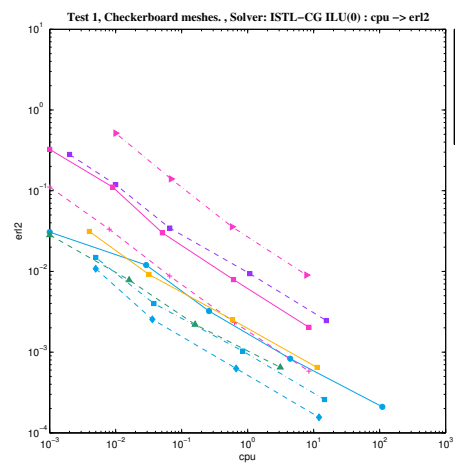

(a) ISTL-CG ILU(0): cpu $\rightarrow$ erl2

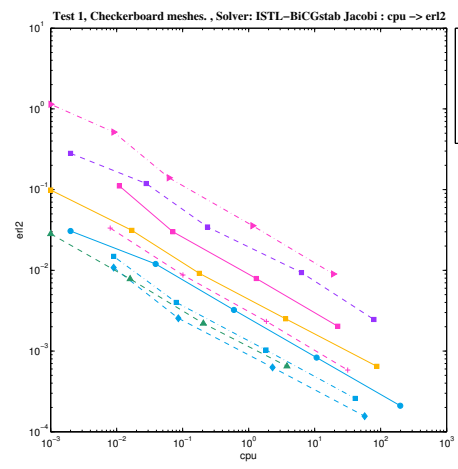

(c) ISTL-BiCGstab Jacobi: cpu $\rightarrow$ erl2

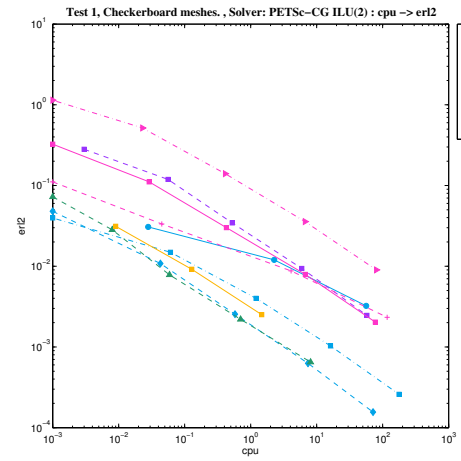

(e) PETSc-CG ILU(2): cpu $\rightarrow$ erl2

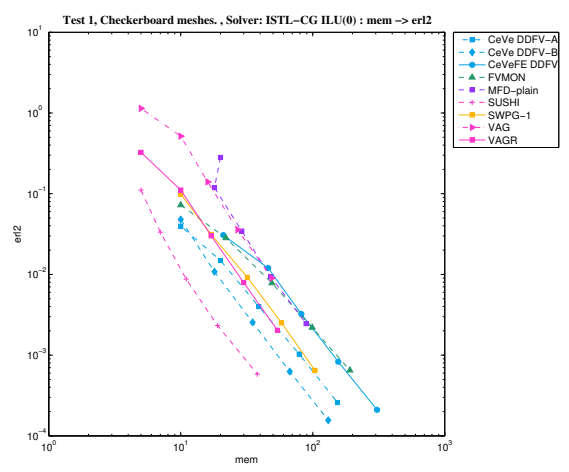

(b) ISTL-CG ILU(0):memory $\rightarrow$ erl2

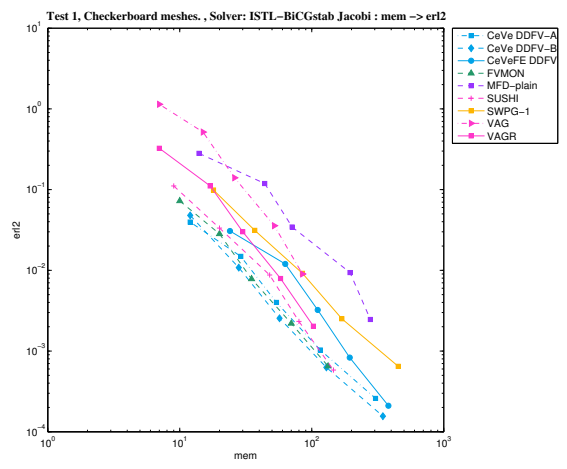

(d) ISTL-BiCGstab Jacobi:memory $\rightarrow$ erl2

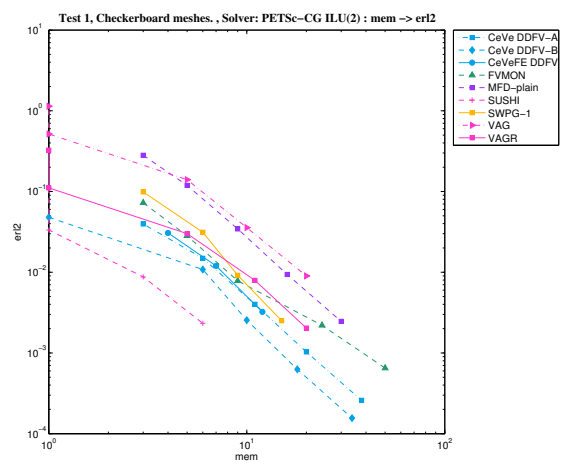

(f) PETSc-CG ILU(2): memory $\rightarrow$ erl2

Fig. 14 Test 1-Checkerboard meshes. 


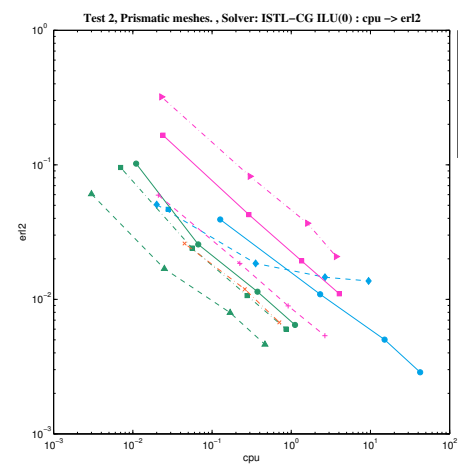

(a) ISTL-CG ILU(0): cpu $\rightarrow$ erl2

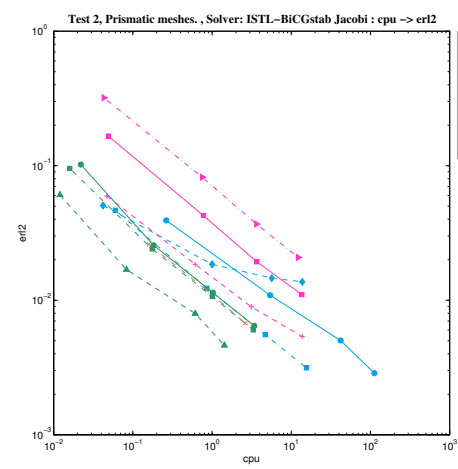

(c) ISTL-BiCGstab Jacobi: cpu $\rightarrow$ erl2

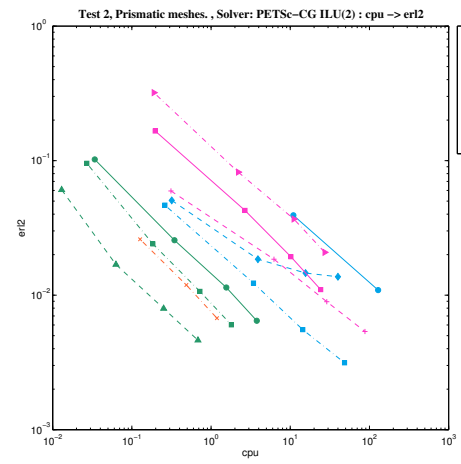

(e) PETSc-CG ILU(2): cpu $\rightarrow$ erl2
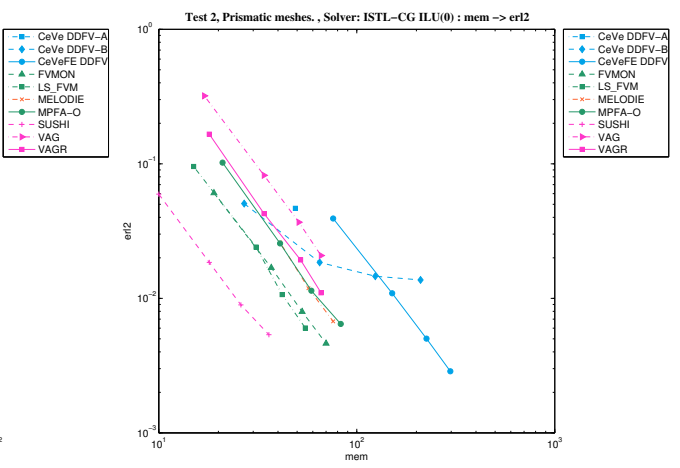

(b) ISTL-CG ILU(0):memory $\rightarrow$ erl2
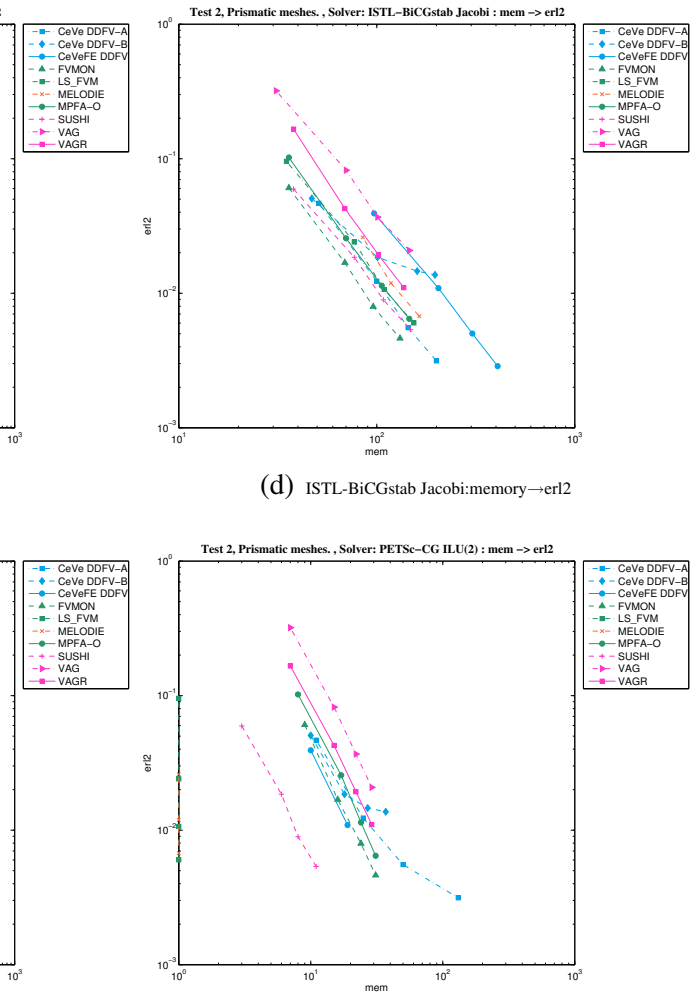

(f) PETSc-CG ILU(2): memory $\rightarrow$ erl2

Fig. 15 Test 2-Prismatic meshes. 


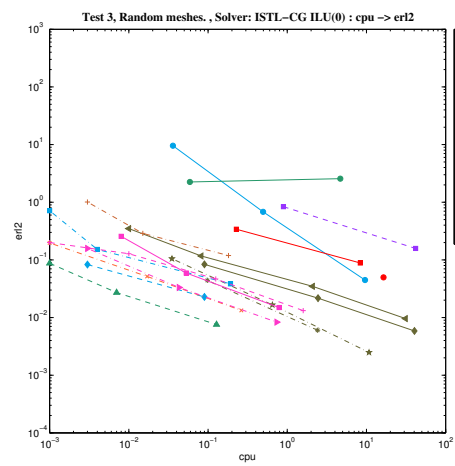

(a) ISTL-CG ILU(0): cpu $\rightarrow$ erl2

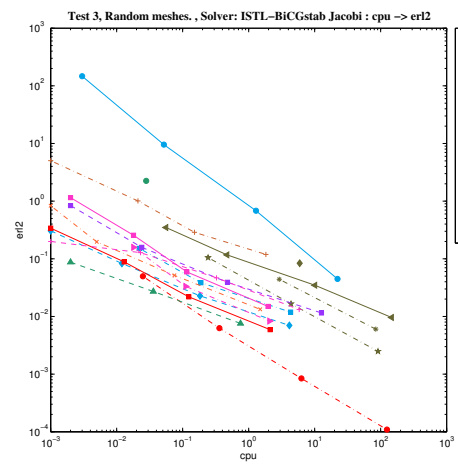

(c) ISTL-BiCGstab Jacobi: cpu $\rightarrow$ erl2

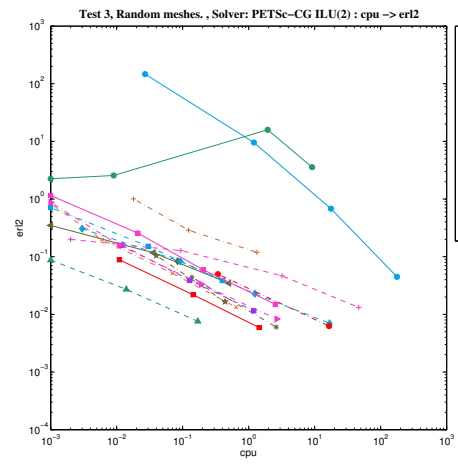

(e) PETSc-CG ILU(2): cpu $\rightarrow$ erl2

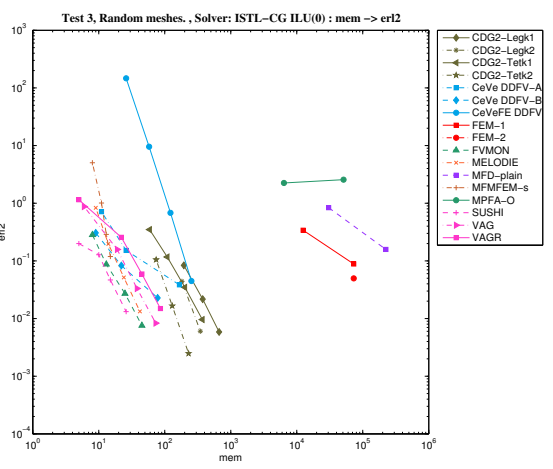

(b) ISTL-CG ILU(0):memory $\rightarrow$ erl2

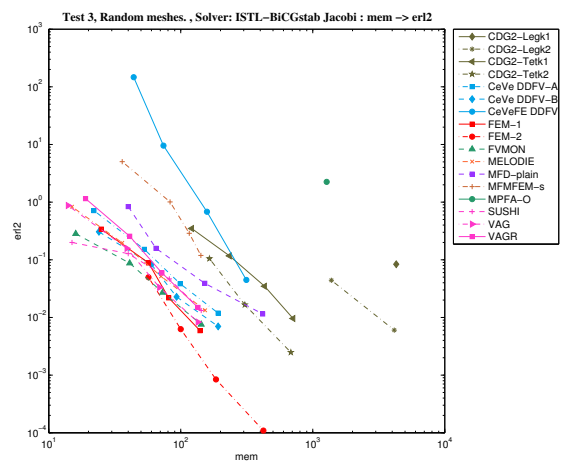

(d) ISTL-BiCGstab Jacobi:memory $\rightarrow$ erl2

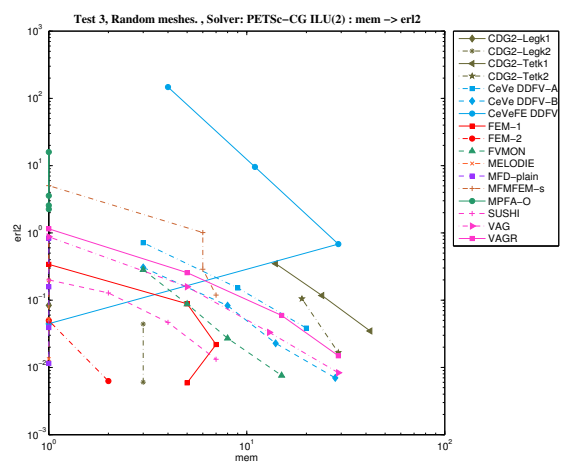

(f) PETSc-CG ILU(2): memory $\rightarrow$ erl2

Fig. 16 Test 3-Random meshes. 




(a) ISTL-CG ILU(0): cpu $\rightarrow$ erl2

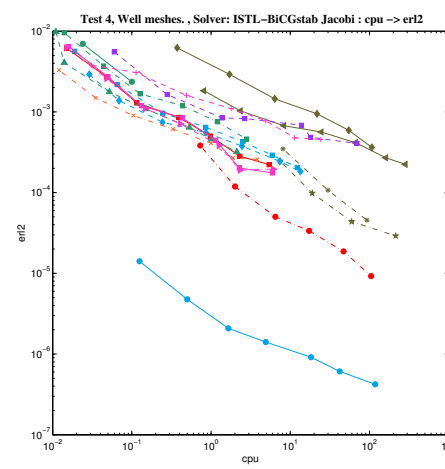

(c) ISTL-BiCGstab Jacobi: cpu $\rightarrow$ erl2

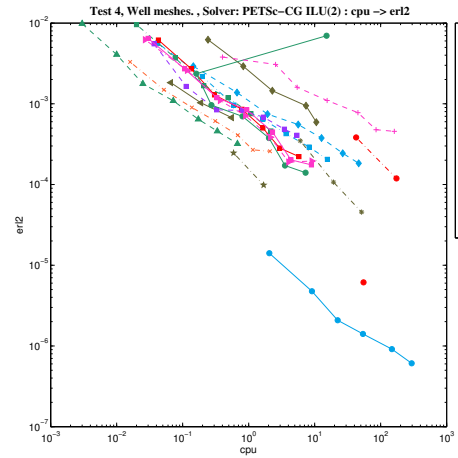

(e) PETSc-CG ILU(2): cpu $\rightarrow$ erl2
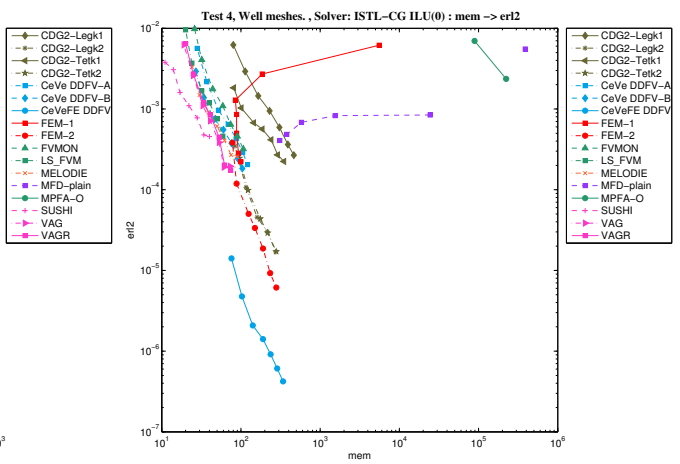

(b) ISTL-CG ILU(0):memory $\rightarrow$ erl2

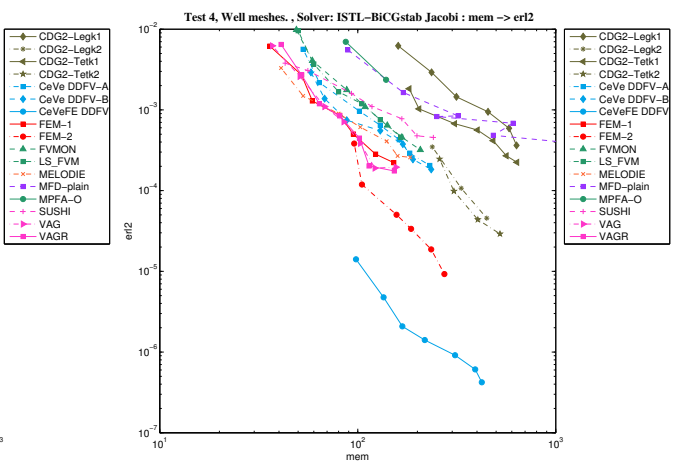

(d) ISTL-BiCGstab Jacobi:memory $\rightarrow$ erl2
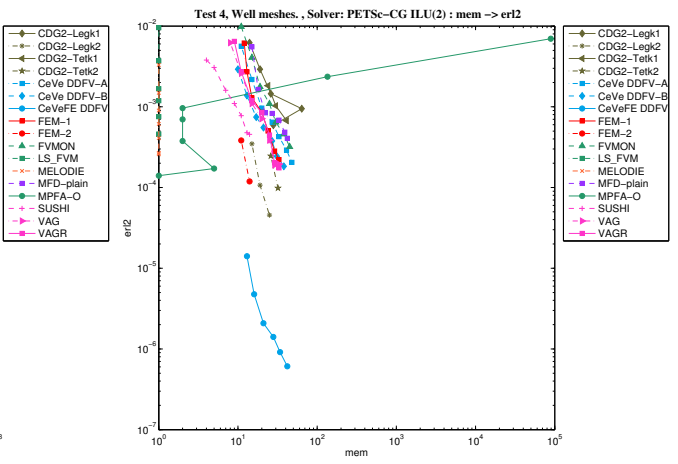

(f) PETSc-CG ILU(2): memory $\rightarrow$ erl2

Fig. 17 Test 4- Well meshes. 


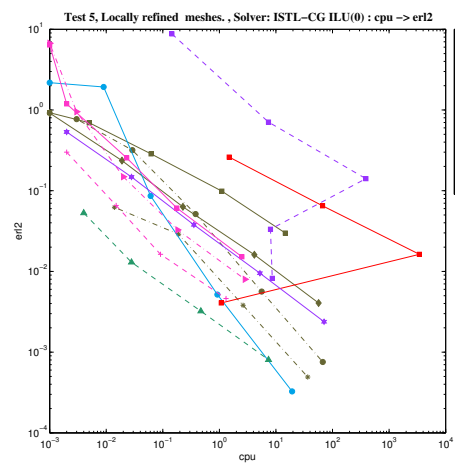

(a) ISTL-CG ILU(0): cpu $\rightarrow$ erl2

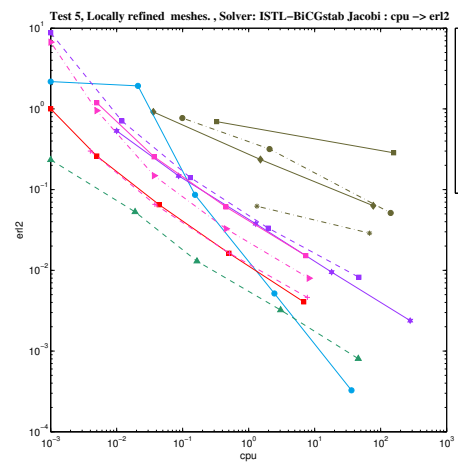

(c) ISTL-BiCGstab Jacobi: cpu $\rightarrow$ erl2

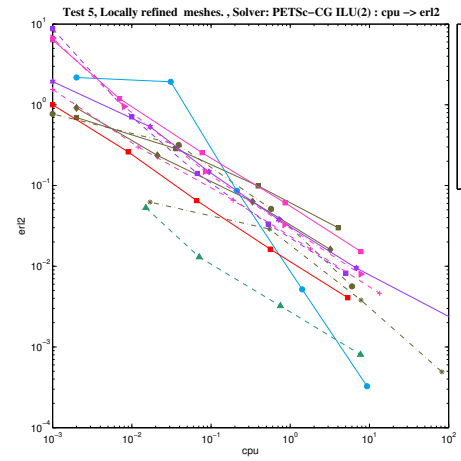

(e) PETSc-CG ILU(2): cpu $\rightarrow$ erl2



(b) ISTL-CG ILU(0):memory $\rightarrow$ erl2

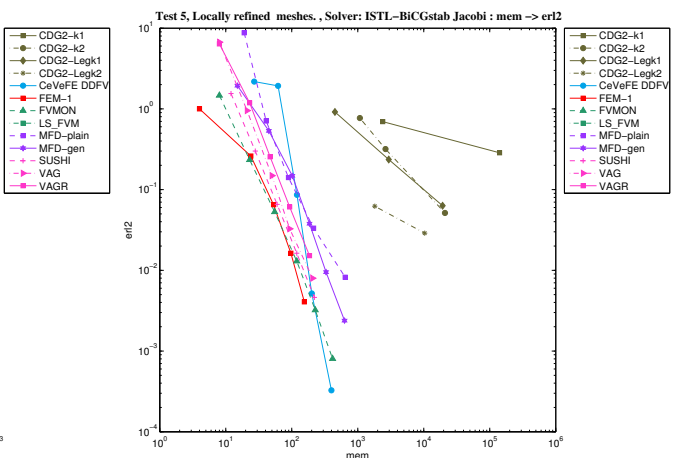

(d) ISTL-BiCGstab Jacobi:memory $\rightarrow$ erl2
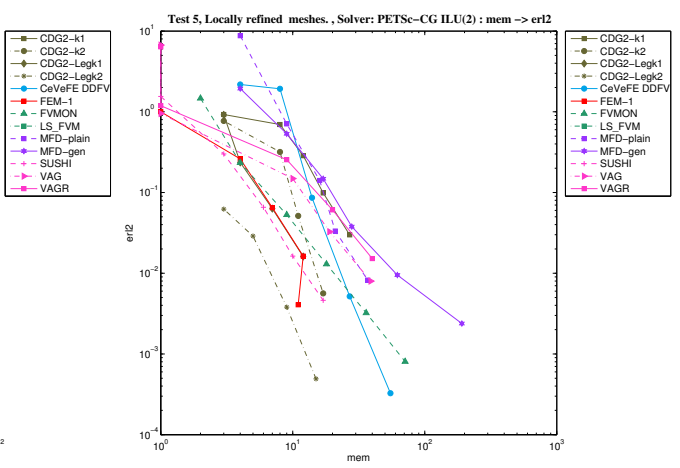

(f) PETSc-CG ILU(2): memory $\rightarrow$ erl2

Fig. 18 Test 5-Locally refined grid. 